\title{
9 Case studies and applications
}

\subsection{Implementation of defluoridation filters in Ethiopia}

Lars Osterwalder, Anja Bretzler, Alexandra C. Huber, Richard B. Johnston, Hans-Joachim Mosler, Hong Yang, C. Annette Johnson

\section{Background}

It is estimated that more than 8 million people live in fluoride-affected areas in Ethiopia (Rango et al., 2012 and references therein). The main sources of fluoride are basaltic rocks, which have both elevated fluoride content and low soluble calcium concentrations. In the Ethiopian Rift Valley, over $40 \%$ of deep and shallow wells are contaminated, and fluoride levels are often significantly higher than the present international WHO guideline value of $1.5 \mathrm{mg} / \mathrm{L}$ (Tekle-Haimanot et al., 2006). As a result, dental and skeletal fluorosis is widespread among the population of the Rift Valley. The mitigation of this health problem has been hampered mainly by the lack of suitable, inexpensive removal methods and technical support. A switch to treated surface waters for drinking is being discussed, but it is accepted that fluoride removal systems for rural communities are required, at least until longer-term solutions can be put in place. Therefore, in 2009, in collaboration with Addis Ababa University, Eawag launched the research project, "Optimization and acceptance of fluoride removal options in rural Ethiopia", funded by the Swiss National Science Foundation and the Swiss Agency for Development and Cooperation.

\section{Aim}

The aim of the project was to combine technical and social research with field implementation to find a suitable and acceptable solution for the problem of fluoride contamination in drinking water in rural Ethiopia:

- To compare and optimise the removal efficiency of two different filter materials in the laboratory and subsequently to test the performance of these technologies in the field

- To assess the personal, social and situational factors that influence the continuous use of fluoride removal systems by the rural population

- To investigate the institutional settings and identify stakeholders' interests and preferences for the implementation of fluoride removal

- To investigate fluoride uptake pathways via food and water

- To strengthen the institutional capacity for research and implementation in Ethiopia

Intensive interaction between physical and social sciences was indispensable in this project, because even the best technical solution is useless when it is not accepted by the 
population. Another important goal of this collaborative project was capacity building and human resource development in Ethiopia. It included a south-south knowledge transfer between Kenya and Ethiopia that was aimed at strengthening the research capacity of the Addis Ababa University. The participation of NGOs consolidated the ties between research and implementation. Furthermore, the results should be applicable not only to Ethiopia but also to other fluorosis-affected developing countries.

\section{Partners}

Addis Ababa University (AAU): Main research partner of Eawag. The Chemistry Department developed an aluminium-based filter medium (AO). The institutional analysis of the Ethiopian water sector was conducted through the Department of Political Science and International Relations.

Nakuru Defluoridation Company Limited (NDC): Producer of high-quality bone char and calcium phosphate pellets in Nakuru, Kenya. Eawag and NDC have been working jointly on optimising the Nakuru Technique since 2006. NDC provided bone char and pellets to the research project.

Oromia Self-Help Organization (OSHO): Local NGO and field implementation partner of Eawag. Since 2007, OSHO has been introducing bone char household filters funded by Swiss Interchurch Aid (HEKS), with technical support from Eawag and NDC.

National Fluorosis Mitigation Project Office (NFMPO): The office is currently located at the Ministry of Water and Energy and took up work in 2009. Information was exchanged regularly with other project partners.

Key stakeholders that were involved in the project included water offices at national, regional, zone and district levels, development partners interested in fluoride mitigation, Ethiopian research institutions, water committees and beneficiaries in the project villages. A number of workshops with stakeholder participation were held during the course of the project to strengthen stakeholder involvement in decision-making and to disseminate results.

\section{Integrative approach}

Two community fluoride removal filters were constructed in the Ethiopian Rift Valley for detailed field testing, one using the Nakuru Technique (Section 5.3) and one using aluminium (hydr)oxide ("AO", a filter media developed by Addis Ababa University). The filter sites were selected during a workshop in Addis Ababa in November 2009, in consultation with representatives from regional, zone and district (woreda) water offices. For the sake of convenience, only the results from the community filter using the Nakuru Techniques in Wayo Gabriel village are discussed in this chapter (see Fig. 9.1). 
A separate meeting was held with the local water committee, village administrators and a district representative to set the tariff for treated water in time for the opening of the filter. The water committee is an elected group of people from the village responsible for managing a water scheme. Individuals usually have to pay for drinking water in the Ethiopian Rift Valley, so paying for water was not a new concept. The intention was to set a water tariff that covered the operator's salary plus more than $50 \%$ of the costs during filter media replacement during the three-year project, and to explore the potential of $100 \%$ medium-cost coverage in collaboration with OSHO for the long term.

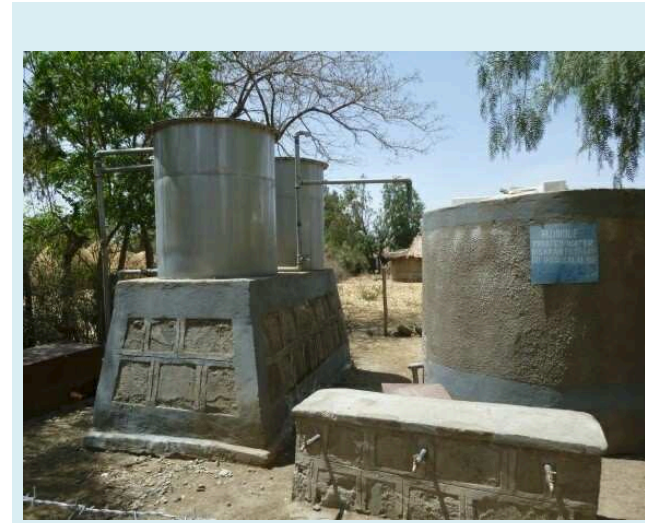

Community Filter using the Nakuru

Technique

(Inauguration in May 2010)

Wayo Gabriel, Dugda Woreda, Oromia

Region

(approximately 320 households)

Connected to a small piped water supply

system with a fluoride concentration of $3 \mathrm{mg} /$

L

Water tariff: 0.50 ETB (about USD 0.03) per $20 \mathrm{~L}$ jerrycan

Tank $A$ is filled with $900 \mathrm{~L}$ calcium

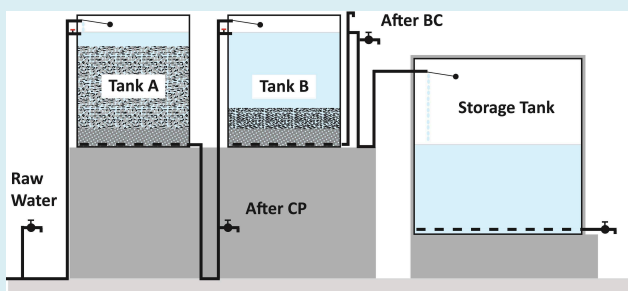
phosphate pellets mixed with $300 \mathrm{~L}$ bone char, and tank B with $300 \mathrm{~L}$ bone char*. All are imported from NDC, Kenya.

* The bone char layer is placed in Tank B for research purposes. For normal operation, all material is first placed in one tank. The second one would be filled when the fluoride level exceeds the desired fluoride level in the first tank.

Fig. 9.1 Technical details of the community filter in Wayo Gabriel

The filter design was adapted from the one-tank systems used by NDC in Kenya to a more sophisticated version that guarantees optimal utilisation of the filter medium. The system consists of two filtration tanks in series $\left(2 \mathrm{~m}^{3}\right.$ each), of which either can be used as the main tank (first) or the polishing tank (second). When fluoride breakthrough occurs, the filter medium in the main tank is replaced and the flow reversed (the main tank with the fresh filter medium then becomes the polishing tank, and vice versa). A storage tank for the treated water $\left(5 \mathrm{~m}^{3}\right)$ allows a slow and continuous water flow, while providing sufficient reserves for times of greater demand. (From previous laboratory experiments, it is known that the fluoride uptake capacity of the Nakuru Technique increases with reduced flow rates). The system is sufficiently simple to handle, so that the operator, 
usually someone from the village, does not need special skills except for some basic training. The operator is also in charge of collecting the water fee from the users.

The different components of the integrated study are shown in Figure 9.2.

\section{Fluoride uptake through food and water}

To determine the amounts of fluoride ingested through food and water, interviews were conducted with 20 families on their daily diet over the previous seven days and on recipes for the most common dishes. Based on this information, the most commonly consumed food ingredients were collected in nine households around Wayo Gabriel and analysed for their fluoride content. The selected households collected drinking and cooking water from three different water sources with fluoride concentrations of $0.75 \mathrm{mg} / \mathrm{L}$ (average of water treated at the community filter $0-1.5 \mathrm{mg} / \mathrm{L}), 3 \mathrm{mg} / \mathrm{L}$ and $10 \mathrm{mg} / \mathrm{L}$. Using the information from the interviews and the results from the analysis to estimate mean daily consumption, the mean daily fluoride uptake through food and water was calculated.

\section{Filter performance}

Data on the quality and consumption of the treated water were collected in order to analyse the fluoride removal performance of the filter and to guarantee safe drinking water for the consumers. Weekly measurements of fluoride concentrations were conducted and water meter readings taken to find out how much water had been consumed. On a monthly basis (and more frequently during the first few months), water samples were taken from all four sample taps (raw and treated water after Tank A and after Tank B), and a complete chemical analysis was carried out. Fluoride measurements were generally conducted every week.

\section{Behavioural change}

In both villages with community filters, a baseline survey to determine the psychological factors that influence the desired behaviour (using fluoride-free water for drinking and cooking) was conducted using structured questionnaires in 100 randomly selected households in each village. Three different behavioural change campaigns (interventions) were then undertaken to promote the use of the filtered water.

Surveys were conducted after each intervention and at the end of the 18-month promotion period. A team of ten local college students were recruited and trained to conduct the interviews. The duration of one interview was, on average, one hour per household; the questionnaires were translated into Amharic and Oromifa.

\section{Institutional analysis}

This task was performed in four steps.

Step 1: Stakeholders involved in fluoride mitigation in Ethiopia were identified through literature review and contacts with experts in the field. 
Step 2: Seventy end-users in the field (35 of them in Wayo Gabriel) were interviewed personally by the $\mathrm{PhD}$ student about affordability and access to safe drinking water, using semi-quantitative questionnaires.

Step 3: Representatives from water offices at different levels, development partners and members of the National Fluorosis Mitigation Technical Advisory Committee were selected and interviewed, using a qualitative questionnaire, about sustainability, preferences, opportunities and the threats of different fluoride mitigation options.

Step 4: A Multi-criteria Decision Analysis (Section 9.3) was carried out during the final project workshop to compare stakeholders' preferences which referred to different fluoride removal technologies.

\section{Cost and Affordability}

One of the most important aspects that needs to be addressed in order to achieve sustainable and successful fluoride mitigation in Ethiopia is the issue of cost. When donor funding runs out, can the costs of fluoride removal still be covered? Within this case study, an analysis of the expenditures that need to be taken into account when installing and managing a fluoride removal filter was carried out. More details about the individual cost components can be found in IRC (2011).

Capital Expenditure (CapEx): These are the funds that need to be invested in fixed assets, such as filter tanks and pipes, in initial awareness raising campaigns and in training operators, in the water committee and the district water office. CapEx can pose a significant investment at the start of a project.

Capital Maintenance Expenditure (CapMEx): Occasional cost of renewing (replacing, rehabilitating, refurbishing) essential parts of the system (e.g. filter material) in order to ensure that services continue at the same level of performance that was first delivered.

Operation and Minor Maintenance Expenditure (OpEx): Cost of daily operation and light maintenance (e.g. power, salary of operator). OpEx does not include costs of major repairs.

Expenditure on Direct Support: Pre- and post-construction support activities directed at local stakeholders and users. This could include monitoring, technical advice, administrative or organisational support, conflict resolution, capital maintenance, training and refresher courses, the provision of information and resource mobilisation. 


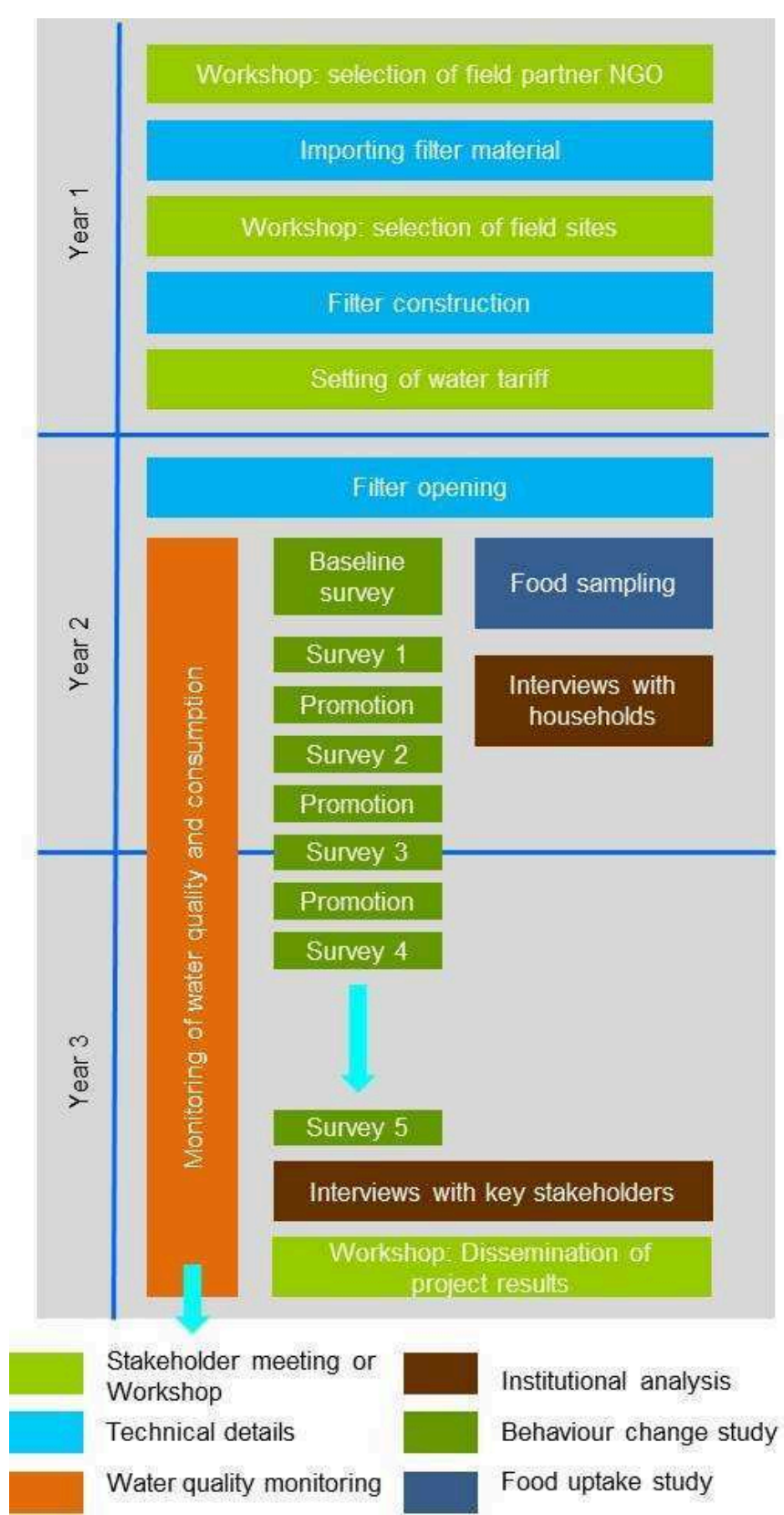

Fig. 9.2 Project planning overview 


\section{Results}

\section{Fluoride uptake through food and water}

The total average fluoride intake of an adult consuming treated water for drinking and cooking from the community filter was estimated to be around $6 \mathrm{mg} /$ day. (For comparison, the daily fluoride intake of an adult consuming water with $10 \mathrm{mg} / \mathrm{L}$ is $25 \mathrm{mg} /$ day.) This is close to the tolerable upper intake level (Table 3.3).

\section{Filter performance}

The Nakuru Technique community filter was not saturated at the end of the research project, mainly due to an initially low water consumption. Based on the experience of NDC in Kenya, it was expected that the filter could treat at least another 750 to $1000 \mathrm{~m} 3$ until fluoride breakthrough, if not more, because of the improved design compared to the NDC filters. Nevertheless, the field test in Ethiopia revealed two major challenges remaining for this optimised and more sophisticated filter design:

Slow and continuous flow: The stainless steel tanks could not be pressurised as planned because of leaks in the lid seal. Instead, the operator needed to turn the main water line on and off manually. As a result, water passed rapidly through the filter tanks for only a few hours instead of the intended slow and continuous flow over 24 hours. This is the reason for the fluoride level fluctuation after tank A (see Fig. 9.3). Nevertheless, the bone char layer was still able to remove all remaining fluoride.

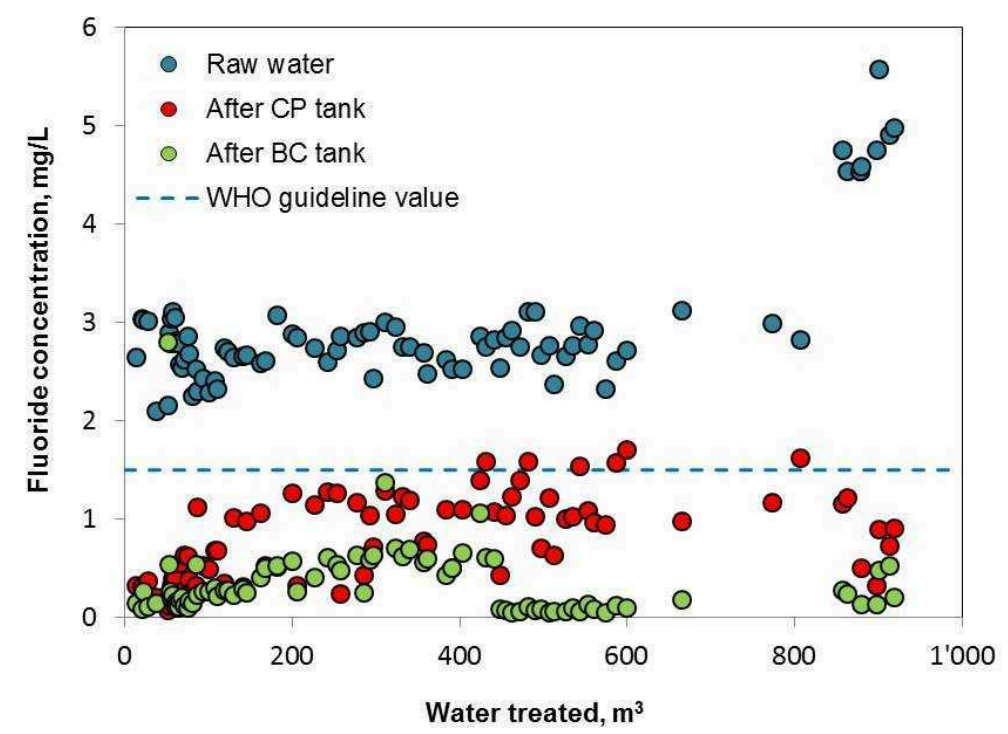

Fig. 9.3 Results of fluoride monitoring from 20.05.2010 to 28.02.2013 in the Nakuru Technique filter. CP: contact precipitation ("Nakuru Technique"), BC: bone char. At around $800 \mathrm{m3}$, the concentrations of fluoride and salts in the raw water rises.

Two interchangeable filter tanks: The operation proved to be more complicated than expected. After $50 \mathrm{~m}^{3}$ of water had been treated, a wrong valve was opened, and raw water bypassed the system. After this incident, another valve was not completely closed, 
and some water passed only through tank $A$ but not through tank $B$. This was noticed and rectified after $450 \mathrm{~m}^{3}$ of water had been treated.

These problems were finally resolved by installing float valves in the two filter tanks to control the water flow automatically. A detailed operation manual for the filter is being developed in participation with OSHO, district water officers and community filter operators.

\section{Behaviour change}

The baseline survey in Wayo Gabriel revealed that the consumption of fluoride-free water was hindered mainly by (i) high perceived costs but also by (ii) perceived taste, (iii) perceived ability and (iv) commitment (Section 8.3, Huber and Mosler, 2012; Huber et al., 2012). Furthermore, the behaviour of others had a strong influence on individual households (people who think that many others are also collecting water from the community filter are more likely to collect water from the same source themselves). Based on this understanding of psychological factors, the following interventions were conducted to increase the consumption of fluoride-free water and to keep consumption sustainably high (Huber et al., 2014; Fig. 9.4):

Phase 1: Persuasion campaign. Households were visited by a health promoter who was trained in persuasion techniques to tackle perceived costs (determined by the baseline survey to be an important factor) and perceived vulnerability (conventional wisdom holds that raising awareness about the severity of health effects may stimulate behaviour change).

Phase 2: Photo promotion. People that fetched water at the community filter had their picture taken, and they received these with a reminder slogan added below the picture (Fig. 9.4). The promotion aimed to motivate new users to try filtered water and to help people (with the picture as a reminder) to remember fetching water at the community filter.

Phase 3: Flag promotion. Households were again visited by promoters and asked to commit themselves to consume only fluoride-free water in the future. A blue flag was installed on the household's roof to make their commitment public. The aim of this was to increase people's commitment and at the same time, to inform other villagers that the people in that particular household were consuming treated water.

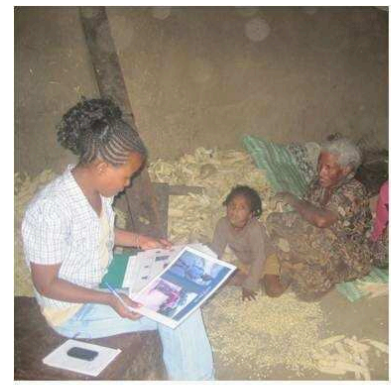

Persuasion

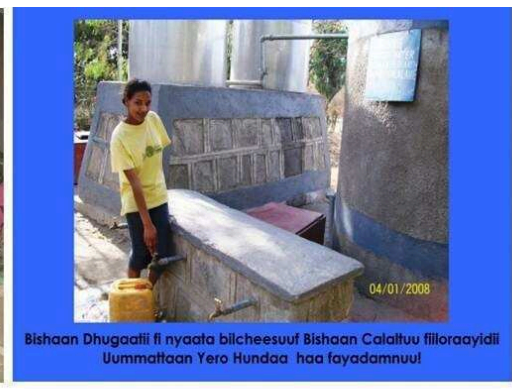

Photo promotion

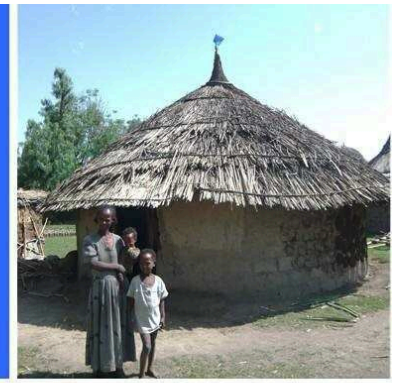

Flag promotion

Fig. 9.4 Behaviour change interventions 
An increase in fluoride-free water consumption by people who had received the photo reminder and had put it up on the wall where it was visible was observed in Phase 2 . The flag promotion in Phase 3 resulted in an increased average fluoride-free consumption of all households in the area. People who had committed themselves and had a flag on their roof increased consumption significantly more than others. However, an increase in fluoride-free water consumption was also observed by those who had not received the commitment intervention. They probably saw the flags all over the village and therefore realised that many of their neighbours were using fluoride filtered water.

After a 6-month break during which no surveys or interventions were carried out, the longterm effectiveness of the behaviour-change activities was evaluated. Most photos and flags were still in place, and all of the households that had switched to the consumption of fluoride-free water were still buying this water. The overall consumption was still high, even though people without any intervention slightly decreased their consumption. In general, it can be concluded that the promotion strategies were very successful in increasing and maintaining the consumption of fluoride-free water within the community, with the exception of the "conventional wisdom" intervention targeting awareness of the risk of contracting fluorosis.

\section{Institutional analysis}

Figure 9.5 shows stakeholders that were identified as being active in fluoride mitigation in Ethiopia. Many are supportive, and a few stakeholders are neutral or unsupportive. The National Fluorosis Mitigation Project Office (NFMPO) was found to have established a reasonable basis for coordination and communication between different stakeholders. An important point to be addressed in the near future is the location of the NFMPO; i.e. whether it should be embedded in the existing institutional structure of the Ministry of Water and Energy (MoWE) or whether it should be set up independently in a research institute or a university. There are several organisations that could become more involved. Of these, the Ministries of Health and Education would be important partners. 

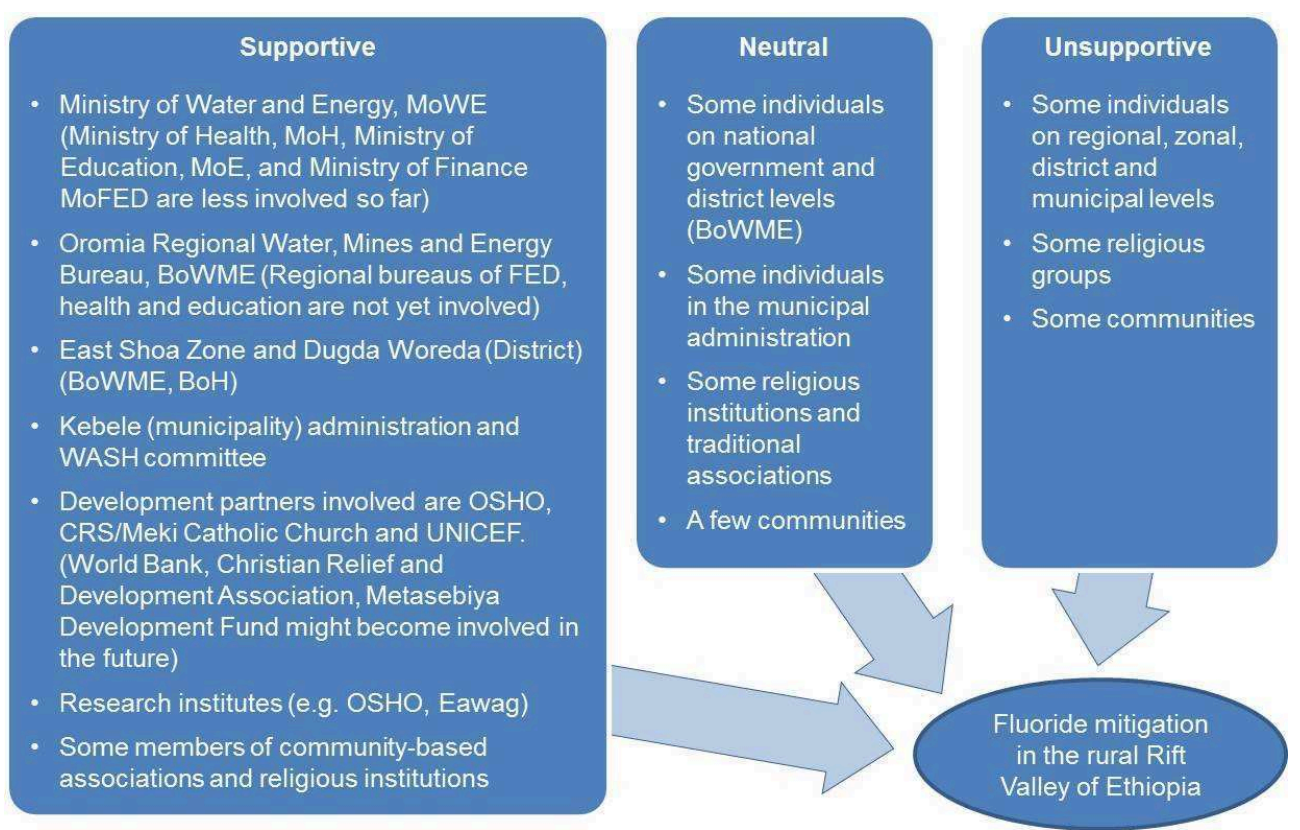

Fig. 9.5 Map of stakeholders involved in fluoride mitigation in the Ethiopian Rift Valley

\section{Cost and affordability analysis}

Under the current situation, when all types of costs are considered, rural communities in Ethiopia are not (yet) able to afford fluoride removal activities without significant subsidies from other sources such as governments or NGOs. This is especially the case when fluoride concentrations in the raw water are high, and the filter material needs frequent replacement or regeneration. There is a remaining need for fluoride mitigation options to be developed or adapted in order to achieve higher cost-effectiveness. Organisations that are implementing fluoride removal units need to assess carefully the willingness and ability of stakeholders (beneficiaries, government, NGOs) to cover certain types of costs sustainably. Cost indicators should be included in the monitoring procedure.

\section{Conclusions}

The results of the intake analysis show that a high percentage of fluoride is taken up via water used for drinking and cooking. If fluoride-contaminated water is treated with a removal technique, a significant reduction in the risk of developing skeletal fluorosis can be expected. The Nakuru Technique fluoride removal community filter in Wayo Gabriel can reduce fluoride concentrations to below the WHO guideline of $1.5 \mathrm{mg} / \mathrm{L}$, although the fluoride uptake capacity should be increased further to make the system more costeffective (and reach 100\% cost coverage by the local community). The adapted filter design could contribute to achieving this goal, but only if the operation is carried out properly. It was shown that the Nakuru Technique is well accepted by consumers. This contradicts previous studies that stated that bone char is generally culturally not acceptable in Ethiopia. It was also shown that simply providing a filter is not sufficient; in Wayo Gabriel, it was only after well-designed promotional campaigns that the majority of 
consumers used fluoride-free water for drinking and cooking purposes. However, fluoride exposure through food remained at levels high enough to cause dental, and possibly also skeletal, fluorosis. While reducing fluoride exposure through water is necessary to mitigate fluorosis, it is not sufficient. The results of the Ethiopian case study were communicated to the major stakeholders during a two-day workshop in April 2012 in Addis Ababa.

\section{Recommendations}

- More focus on the "software" components. Capacity building for local authorities and NGOs in effectively promoting behaviour change in communities, combined with close monitoring of the consumption of fluoride-free water.

- Close monitoring and documentation of newly installed fluoride removal options during the first few years to further optimise filter design and to obtain information on real filter performance and costs.

- Reduction in the overall costs of defluoridating drinking and cooking water. This could include optimising the production of the filter media, regeneration or reuse in agriculture and testing of newly developed, low-cost filter media in the field.

- Increased involvement of health authorities in fluoride mitigation by supporting a combination of fluoride removal with microbiological drinking-water treatment, sanitation and hygiene promotion. Health impact studies could complement further fluorosis mitigation activities.

- Food intake represents a significant source of fluoride exposure. Strategies need to be developed to reduce fluoride exposure through foodstuffs through changes in either agricultural or cooking practices. 


\subsection{Assessing stakeholder preferences in Bangladesh}

Richard B. Johnston, Stephan J. Hug, Jennifer Inauen, Nasreen Khan, Hans-Joachim Mosler, Hong Yang, C. Annette Johnson

\section{Background}

Widespread arsenic contamination of shallow $(<150 \mathrm{~m})$ and some deep tubewells was first identified in 2000 (BGS/DPHE, 2001). Of the total population of 125 million in Bangladesh, it was estimated that 57 million were exposed to arsenic concentrations above the WHO provisional guideline value of $10 \mu \mathrm{g} / \mathrm{L}$, while 35 million were consuming water with concentrations above the Bangladesh Drinking Water Standard of $50 \mu \mathrm{g} / \mathrm{L}$. Early mitigation efforts focused on technologies such as pond sand filters and hand-dug wells, but these options are more vulnerable to faecal contamination. It was estimated that in comparison to shallow tubewells, deep tubewells were predicted to cause a much lower burden of disease (Howard el., 2006). Deep tubewells were not prioritised in the 2004 national policy and implementation plan because of concerns that deep tubewells might not be free of arsenic in some regions, or that abstraction of deep groundwater could induce downward transport of arsenic from contaminated shallow aquifers. While deep groundwater in certain regions (notably parts of Jessore, Satkhira and the Sylhet Basin) can contain arsenic under specific geological conditions, the last decade has shown that deep tubewells are geochemically stable and that the feared draw-down does not occur as long as large volumes of water for irrigation purposes are not abstracted from deep aquifers. These results have given impetus to the already preferred deep tubewell mitigation option. As the capital costs of drilling deep tubewells are high, subventions were necessary. Government programmes contribute $90 \%$ of the installation costs.

A second national survey in 2009 found that exposure to $10 \mu \mathrm{g} / \mathrm{L}$ may have been reduced by roughly a quarter (although this just keeps up with population growth) and that exposure to higher concentrations $(>200 \mu \mathrm{g} / \mathrm{L})$ may have been reduced even further (UNICEF/BBS, 2011). As tubewells have a limited lifetime, new wells are continually being drilled, though arsenic is not always monitored (van Geen et al, 2014).

Ensuring that tens of millions of people exposed to arsenic have access to and use safe water is an extremely complex and expensive task, and though progress has been made, there is still a long way to go. The work presented here is based on Johnston et al. (2014).

\section{Aim}

The aim of the project was to learn from the experience gained in Bangladesh. Specifically, the aims were:

- To obtain an understanding of existing institutional support for arsenic mitigation

- To elicit households' willingness to pay for obtaining arsenic-free drinking water and the factors influencing their willingness to pay 
- To assess personal, social, and situational factors that influence the continuous use of arsenic-free drinking water by the rural population

- To determine which factors would best convince householders to use arsenic-free water sources

- To determine the technical factors that limit the use of deep tubewells and how these can be addressed

\section{Partners}

Department of Public Health and Engineering (DPHE) of the Government of Bangladesh. Within the Ministry of Local Government, Rural Cooperatives and Development, DPHE is the lead agency responsible for provision of drinking-water and wastewater management in the country excepting the municipal corporations (Dhaka \& Chittagong) and a number of urban pourashavas. DPHE has worked with Eawag on a survey of deep tubewells in a village in Munshiganj.

UNICEF Bangladesh has been one of the leading agencies responding to the arsenic threat facing Bangladesh. Results of a field survey by Eawag's environmental psychologist team to determine the driving psychological factors that cause people to adopt (or not) new arsenic-safe sources of drinking water have been adopted in UNICEF's arsenic communication strategy. Our team members also coordinated with UNICEF Bangladesh on interpretation of nation-wide drinking water quality surveys.

Bangladesh University of Engineering and Technology (BUET), Dhaka-1000, Bangladesh (Prof A.B.M. Badruzzaman, Prof M. Ashraf Ali). BUET is the country's leading engineering research institute. We have worked together on safe installation of arsenicfree wells in arsenic-affected areas, and on removal of arsenic, iron and manganese from drinking-water.

Dr Kazi Matin Uddin Ahmed, Department of Geology, University of Dhaka is a global expert on arsenic contamination of groundwater. We work together in assessing the quality of groundwater in different geological units, not only in terms of arsenic but other chemical parameters including iron, manganese, and salinity.

Dhaka Community Hospital Trust (DCH Trust): The trust-owned private, self-financed and non-profit organization was established in 1988. Its goal is to provide an integrated and sustainable health care delivery system at an affordable cost in both the urban and rural areas of Bangladesh. Besides basic health care services, the trust is largely involved in disaster management, arsenic mitigation, safe water supply and community based development programs. The $\mathrm{DCH}$ Trust provided logistic support and staff for the institutional field survey in 2010. 


\section{Procedures}

The studies were carried out during the same time period, between spring 2005 and autumn 2011, at sites that were most appropriate for individual investigations.

\section{Analysis of institutions governing mitigation activities}

The institutional study required preparation to obtain an overview of the institutional setting. Problem scoping and site selection were carried out in the following steps:

Step 1: An overview of national and local governmental and non-governmental organisations, policies, regulations, plans, goals and funding (and funding sources) in dealing with geogenic contamination, as well as available mitigation options and the status of their implementation, were obtained by reviewing the relevant literature and by holding discussions with experts in the field.

Step 2: Governmental, non-governmental and international organisations and experts were contacted through local project partners and personal connections to pave the way for taking further steps.

Step 3: Representative sites with different mitigation measures and levels of geogenic contamination, as well as different natural and socioeconomic conditions, were selected.

Two structured face-to-face questionnaire surveys were developed and conducted to obtain the opinions at the institutional and household levels on various aspects of arsenic mitigation in Bangladesh.

Institutional stakeholder surveys were performed in Munshiganj, Comilla and Pabna districts. A stakeholder survey was conducted targeting officials from central and local government, NGOs, and donors involved in arsenic mitigation (Khan and Yang, 2014). The background to the questionnaires and the type of questions asked is outlined below and are also given in Schmeer (1999) and GTZ (2007).

Institutional survey of stakeholders who can affect actions and outcomes

Structured or semi-structured face-to-face interviews should be held with representatives from:

- Central government

- Local government

- NGOs (central and local levels)

- International agencies

- Donor agencies

- Research institutes 
The information to be sought through the interviews should include the following:

- Stakeholders' preferences and interests with regard to different mitigation measures

- Financial resources of organisations involved in mitigation activities (implementation, operation and maintenance of mitigation facilities; e.g. arsenic removal filters)

- Role of different stakeholders in mitigation activities and their influence on these activities;

- Interests and conflicts between different stakeholders.

Understanding the institutional setup at different levels and the interaction between these levels:

- Which institutions/authorities play what roles in managing water resource quality?

- Which are the specific laws, rules or regulations that define these roles (principles, norms, rules, procedures)?

Understanding the available means of execution and enforcement of laws, rules and regulations:

- What laws, rules and regulations exist to assist in the execution, implementation and enforcement of mitigation measures? (There may be none.)

- What means (mechanisms, procedures) are available and have been put in place to enable monitoring and control of compliance to be assessed?

Understanding the forms of governance:

- Are any methods of participatory governance specified?

- What are the participatory governance realities? How is governance organised? Who participates?

Understanding the reality of implementing and enforcing the laws, rules and regulations:

- How well are the laws, rules and regulations implemented and enforced?

- What informal practices exist?

The following example questionnaire is an abbreviated version of the one used for interviewing stakeholders about arsenic mitigation strategies in Bangladesh on the organisational level.

Example: Stakeholder_questionnaire_for_a_survey_at_organisational/policy-level

A householder survey was carried out to determine preferences and willingness to pay for arsenic-free drinking water, as these are critical factors for the success of any mitigation option. The survey was conducted in 13 arsenic-affected rural villages from Sirajdikhan, Sujanagar, Ishwardi and Laksham upazilas (sub-districts). Six hundred and fifty household respondents were asked about their current and preferred water sources and 
usage practices, awareness of arsenic contamination and medical costs related to arsenicosis, as well as their willingness to pay for or contribute to a new alternative water source, namely, deep tubewells (Khan et al., 2014; Khan and Yang, 2014). This is an important issue, because the financing and successful implementation of a mitigation measure may be dependent on the financial contribution of the users. There are a number of approaches for eliciting willingness to pay. The Contingent Valuation Method (CVM) is one of these. This method emerged in the 1960s and has become widely used since the 1990s. More details on conducting willingness-to-pay surveys can be found, for example, in Wedgwood and Sansom, 2003. An outline of the background to the questionnaires and the type of questions asked is given below.

\section{Local community and household surveys (primary stakeholders)}

A structured or semi-structured survey eliciting detailed information relating to:

- Household's sociodemographic characteristics

- Ownership and sources of the drinking-water supply

- Possession of resources, income and expenditure

- Knowledge and awareness of, and local rules and practices for, managing geogenic contamination in drinking water

- Perceptions of the health risks of geogenic contaminants in drinking water

- The cost of treating the associated illness

- End-user willingness to pay (WTP) for the cost of installation and the operation and maintenance (O\&M) costs of various mitigation options.

The questionnaire needs to be pre-tested on pilot sites before a full-scale field survey is conducted. The sample size for the full-scale household survey should be over 300 to allow robust statistical analysis of the data.

The following example questionnaire is an abbreviated version of a questionnaire used for interviewing households on arsenic mitigation strategies in Bangladesh.

Example: Questionnaire_for_household_surveys

\section{Behaviour change}

A series of surveys of the inhabitants of six arsenic-affected districts - Munshiganj, Comilla, Satkhira, Khulna, Bagerhat and Brahmanbaria - was conducted. In all study locations, the people had access to one (or two) of eight arsenic-safe options: dug wells, pond sand filters, piped water supply, household arsenic removal filters, community arsenic removal filters, household rainwater harvesting, deep tubewells or the possibility of the sharing of safe shallow wells. All mitigation options had been installed by the DPHE, UNICEF or local governments.

The purpose was to investigate the acceptance and use of available arsenic-safe water options (Inauen et al., 2013a), including the psychological factors leading to their use (Inauen et al., 2013b; Mosler et al., 2012), and to test behaviour change interventions intended to increase their use (Inauen and Mosler, 2013; Inauen et al., 2013c). The procedures are described in Chapter 8. 


\section{Technical study}

The aim of the technical study was to determine at what depth the water was safe to drink and what measures could be taken to ensure that the right depth had been reached during drilling (Hug et al., 2011). The study site, Munshiganj district near Sreenagar town (a 2.5 by $2.5 \mathrm{~km}^{2}$ area), which lies $30 \mathrm{~km}$ south of Dhaka and $5 \mathrm{~km}$ north of the Ganges River, was selected because over $85 \%$ of shallow tubewells in the Mushiganj district are affected by arsenic concentrations $>50 \mathrm{mg} / \mathrm{L}$.

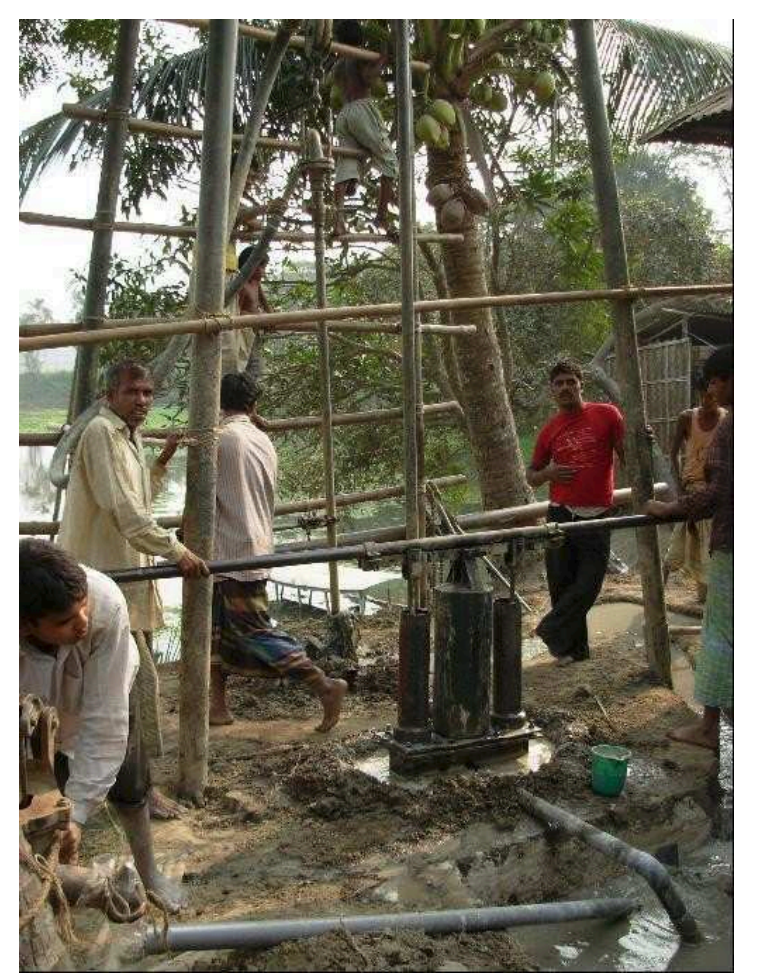

Fig. 9.6 Drilling a deep tubewell

In 3 surveys from 2005 to 2010, samples were collected from existing shallow and deep tubewells, monitoring wells (5-210 $\mathrm{m}$ depth) and newly installed deep tubewells. Electrical conductivity (EC), $\mathrm{pH}$ and dissolved $\mathrm{O}_{2}$ were measured in freshly pumped water with a multi-parameter sensor. Filtered $(0.2 \mathrm{~mm}$, nylon) and unfiltered samples were collected into pre-acidified $(0.15 \mathrm{~mL} 2 \mathrm{M} \mathrm{HCl})$ polypropylene vials $(4 \mathrm{~mL})$ for the analysis of cations (major ions (charges omitted): $\mathrm{Na}, \mathrm{K}, \mathrm{Mg}$ and $\mathrm{Ca}$; minor ions: $\mathrm{Mn}(\mathrm{II}), \mathrm{Fe}(\mathrm{II}), \mathrm{As}_{\mathrm{tot}}$ etc.). For the determination of total organic carbon (TOC), unfiltered samples were collected in preacidified $(0.2 \mathrm{~mL} 5 \mathrm{M} \mathrm{HCl})$ polypropylene vials $(30 \mathrm{~mL})$. For $\mathrm{Cl}, \mathrm{SO}_{4}, \mathrm{NH}_{4}$ (charges omitted) and alkalinity measurements, samples were collected untreated in $50 \mathrm{~mL}$ or $100 \mathrm{~mL}$ polypropylene bottles. The samples were placed in a refrigerator on the day of sampling and cooled to $4-8{ }^{\circ} \mathrm{C}$ until analysis.

A survey involving around 200 deep wells was conducted by Eawag in collaboration with UNICEF and the University of Dhaka in the sub-district of Monoharganj (Comilla). The 
purpose of the survey was to assess the water quality with regard to salinity and to arsenic, manganese and other elements, and to find the best depth for the installation of new deep tubewells. The preliminary results were used as a basis for the installation of deep tubewells in this region by UNICEF and by private donors (e.g. Rotary). Surveys were also conducted on taste and odour, with the purpose of determining acceptable limits for salinity and the concentrations of metal(loid) ions.

\section{Results}

\section{Institutional analysis}

The results presented here are based on Khan and Yang (2014) and Khan et al. (2014).

Stakeholders from all different types of organisations stated that their major roles were to provide arsenic-safe water and to increase awareness of arsenic contamination and exposure among the rural population. The majority (63\%) felt that one of their major achievements had been to increase awareness of arsenic contamination among the rural population, and that as a result of increased awareness, demand for deep tubewells and other alternative arsenic-safe water options had increased. Other major achievements revealed by the stakeholders included the provision of assistance for health-care services related to arsenicosis problems (32\%) and introducing and ensuring safe water options $(27 \%)$.

Surveys at both the institutional and household levels clearly identified deep tubewells and piped water systems as the most preferred options for avoiding arsenic exposure through drinking water. Institutional stakeholders rated deep tubewells as being "highly suitable" (89\%) as a long-term safe water option, followed by piped water systems $(68 \%)$. Rainwater harvesting was also identified as a popular and suitable option in coastal areas of Bangladesh, where groundwater salinity restricts water supply through either deep tubewells or piped water systems. However, household arsenic removal filters were identified as being a "not suitable" option by a majority of institutional stakeholders (63\%), and the household-level survey found that less than $10 \%$ of households interviewed expressed their preferences for household filters as a safe water option. None of the other water options (pond sand filters, dug wells, rainwater harvesting) were significantly favoured by institutional stakeholders, and overall, $50 \%$ of the respondents considered other water options as being "not at all suitable" and only $10 \%$ considered any other water options as "highly suitable". Last but not least, the majority of the institutional stakeholders $(68 \%)$ strongly preferred a community-based safe water option over individual household options.

On average, institutional stakeholders estimated that $50 \mathrm{BDT} /$ month (range 10-250 BDT/ month) until full recovery of installation cost was made would be reasonable. These estimates matched well with household responses: Overall, three quarters of the household respondents were willing to pay $25(32 \%)$ or $50(42 \%)$ BDT for monthly operation and maintenance costs. Household survey results indicated that study households were generally willing to pay up to $5 \%$ of their disposable average annual household income for a one-time investment (capital cost) towards construction of a deep tubewell to receive arsenic-free drinking water (Khan et al., 2014). This low value reflects 
the fact that in the rural villages in Bangladesh, the concept of "paying for water" has not been completely developed, because households can still obtain water without payment. Stakeholders stressed that regular awareness programs would help to develop the concept of "paying for water" in the rural community.

The great majority of the institutional stakeholders $(90 \%)$ agreed that end-users should be willing to walk (WTW) a certain distance for water, while only $10 \%$ believed that end-users should not walk at all for water. Most believed that 0-250 m and 10-30 min per trip were a reasonable distance and time for water collection, without unduly impairing the ability of women (traditionally responsible for water collection in Bangladesh) to manage efficiently their other household work. However, stakeholders also mentioned that religious and cultural issues are also principal factors restricting people's WTW for water. As for cultural factors, in some areas of rural Bangladesh, the women and girls are not encouraged to travel far outside the family home (bari). This can pose a barrier to the collection of water from public sources.

When asked the reasons for the relatively slow progress in arsenic mitigation, the most common response identified by $32 \%$ of institutional stakeholders was the lack of responsibility and accountability. Insufficient funding, lack of coordination and shortage of skilled manpower were all considered as major limiting factors by about $25 \%$ of the stakeholders. They particularly mentioned the locally elected upazila parishad (sub-district councils), whose responsibility it is to identify and mitigate arsenic contamination in drinking water. The stakeholders were of the opinion that greater decision-making power (37\%) along with increased funding and the allocation and retention of trained manpower (74\%) would strengthen capacity at the local government level and hence result in better performance.

Most institutional stakeholders also believed that lack of accountability (32\%) and commitment (11\%) from both providers and end-users, as well as a lack of coordination between organisations (26\%), were the key factors resulting in unsustainable arsenic mitigation. Stakeholders were of the opinion that for sustainable, effective arsenic mitigation by the upazila parishad, the effectiveness of existing arsenic coordination committees was crucial and that this could be enhanced by organising regular meetings and involving experienced people regardless of their political affiliation. Stakeholders also agreed that arsenic mitigation should use a combination of different options suitable to different parts of Bangladesh, and therefore a single blanket mitigation option for the whole country would not be sustainable.

\section{Behaviour change}

The study of eight arsenic-safe water options showed that overall, only $62 \%$ of households with access to a safe water option $(N=1268)$ actually use it (Inauen et al., 2013a). The study also revealed great discrepancies between user rates for the different water options. The most used options were piped water, followed by community arsenicremoval filters, well-sharing, deep tubewells, dug wells, pond sand filters and rainwater harvesting systems (Fig. 9.7). Clearly, if more people would use the options which are accessible to them, the public health burden would be reduced. 


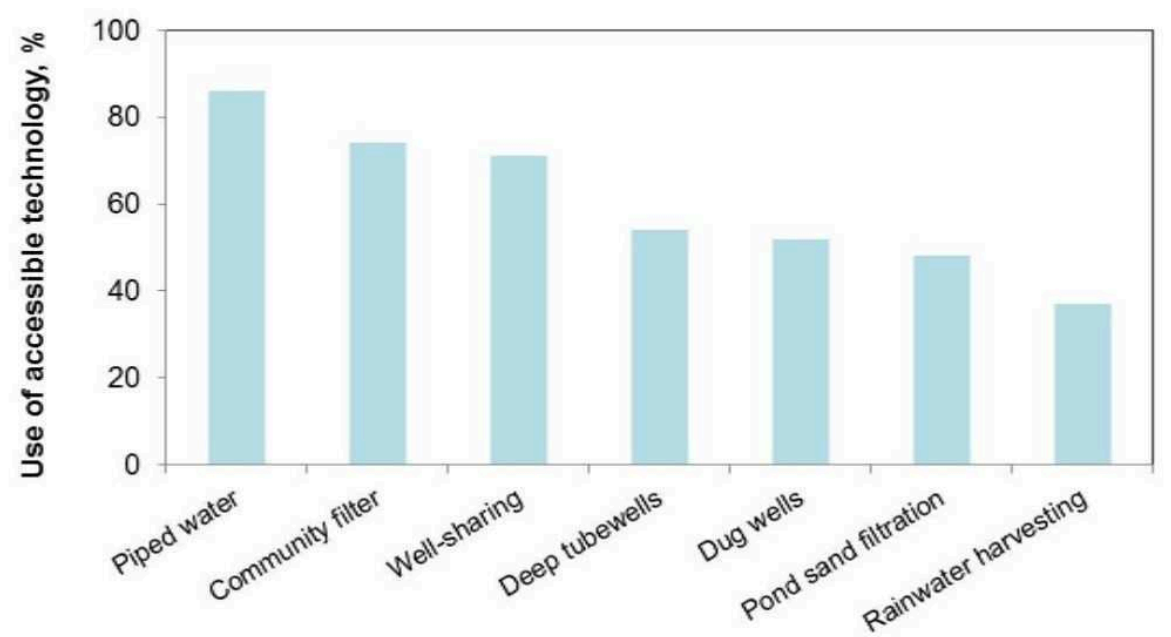

Fig. 9.7 Use of accessible arsenic-free water sources. Household filters were not included, as the data were unreliable (50\% of those who should have had a filter refused to be interviewed).

Psychological factors determined from the RANAS model of behaviour change (risk, attitudes, norms, abilities, self-regulation) (Mosler, 2012) are an aid to better understanding the reasons why some options are preferred over others (Inauen et al., 2013a). A piped water supply was most popular in terms of taste and temperature preferences, followed by strong social norms (i.e. that many relatives and friends are in favour of using arsenic-safe water sources, and that they are also using them), high confidence in their ability to obtain as much arsenic-safe water as needed (i.e., selfefficacy, Bandura, 1997) and high commitment (i.e. a personal desire, Inauen et al., 2013c) to consuming piped water. Interestingly, deep tubewells also enjoy a high degree of acceptance, despite only moderate user rates. This may be due to the fact that collecting water from deep tubewells

has been reported as time-consuming, which may have led to lower commitment (Inauen et al., 2013c). Households with access to neighbours' tubewells only reported below average social norms for using them and low commitment, perhaps also because users are dependent on their neighbours' consent. At the other end of the spectrum, dug wells were perceived as time-consuming and were associated with taste and odour issues.

The next step was to analyse the survey data to forecast the most promising promotion campaigns. Self-efficacy and the descriptive norm (i.e. how many other people use arsenic-safe water options, Cialdini, 2003), emerged as the most important factors to explain the use of arsenic-safe tubewells (Inauen et al., 2013b). Further important factors were instrumental attitudes (i.e. the perception of water collection as time-consuming and hard work) and the injunctive norm (i.e. what one thinks that others think should be done, Schultz et al., 2007). This was applicable to all arsenic-safe water options included in the study. Summarising, these studies indicated that more committed persons, who perceive safe water collection as "normal" and have higher confidence in their abilities to collect safe water, find safe water collection less time-consuming and less of an effort, and those who feel they have more approval from others when they collect arsenic-safe water are more likely to use arsenic-safe water options. 

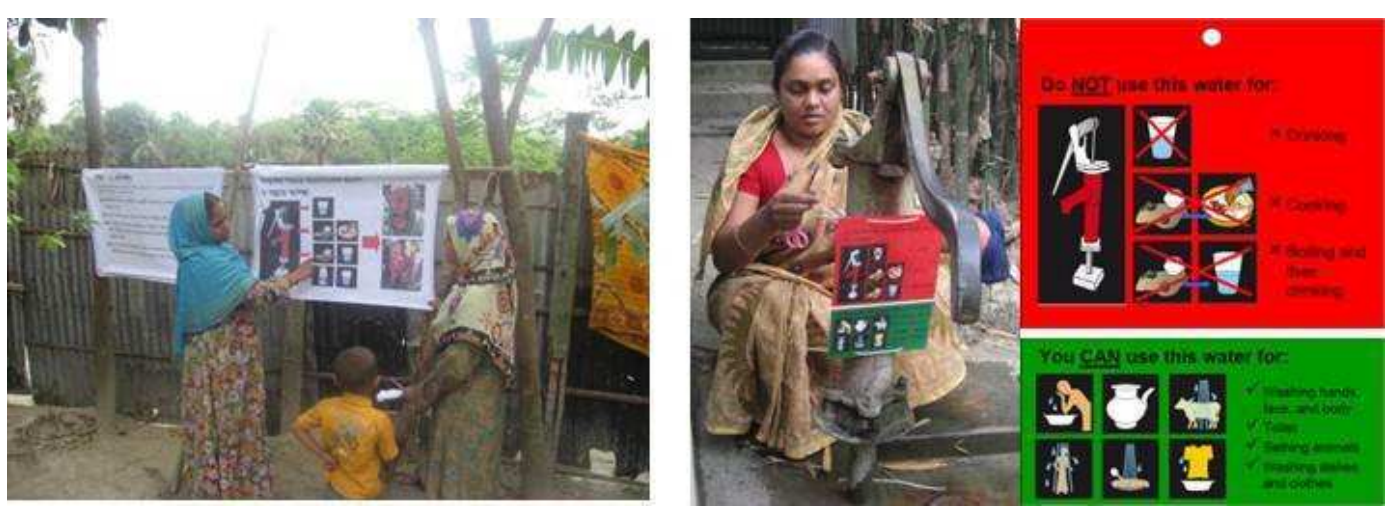

Fig. 9.8 Illustrations of risk information (left) and prompts (right)

Given their general acceptance, deep tubewells were chosen for promotional campaigns to overcome the issues of distance and lack of commitment. To increase commitment, the most promising factor of deep tubewell use, they developed reminders, implementation intentions (simple plans of when, where and how to obtain arsenic-free water, Gollwitzer, 1999) and public commitment (sometimes termed "pledging", Fig. 8.8), and combined them with risk information (Fig. 9.8, Inauen et al., 2013c, Gollwitzer, 1999).

The results of a randomised controlled trial revealed that evidence-based behaviour change techniques increased the behaviour change effect by $50 \%$ compared to simple information provision (Inauen et al., 2013c). But also less "spontaneously" accepted and used arsenic-safe water options can be promoted by targeting any of the psychological factors identified above. For well-sharing, for example, the commitment-enhancing behaviour change techniques described above increased the number of users by up to $66 \%$ (Inauen and Mosler, 2013).

\section{Technical}

The analyses of water from shallow and deep tubewells in the tested area of Sreenagar, Munshiganj, identified three types of groundwater currently used for drinking:

- Shallow water from 20 to $100 \mathrm{~m}$ : dark-grey sediments with high As concentrations (100-1000 mg/L), intermediate to high Fe (2-11 mg/L), intermediate Mn (0.2-1 mg/ $\mathrm{L})$ and relatively low electrical conductivity $(\mathrm{EC})(400-900 \mathrm{mS} / \mathrm{cm})$, dominated by $\mathrm{Ca}-\mathrm{Mg}-\mathrm{HCO}_{3}$.

- Water from 140 to $180 \mathrm{~m}$ : light-grey sediments with low As (<10 mg/L), intermediate $\mathrm{Mn}(0.2-1 \mathrm{mg} / \mathrm{L})$, intermediate $\mathrm{Fe}(1-5 \mathrm{mg} / \mathrm{L})$ and intermediate $\mathrm{EC}$ $(1200-1800 \mathrm{mS} / \mathrm{cm})$, dominated by $\mathrm{Ca}-\mathrm{Mg}-\mathrm{HCO}_{3}-\mathrm{Na}-\mathrm{Cl}$.

- Deep water from 190 to $240 \mathrm{~m}$ : brown sediments with low As (<10 mg/L), high Mn $(2-5 \mathrm{mg} / \mathrm{L})$, low Fe $(<3 \mathrm{mg} / \mathrm{L})$ and high EC $(2000-3000 \mathrm{mS} / \mathrm{cm})$, dominated by $\mathrm{Ca}-$ $\mathrm{Mg}-\mathrm{Na}-\mathrm{Cl}$ with high $\mathrm{Ca}$ and $\mathrm{Cl}$ concentrations.

Drillers have traditionally used the transition from grey to brown sediments as an indicator of the depth from which safe drinking water can be obtained. However, in most of the tubewells in the study area below $190 \mathrm{~m}$, the Mn concentrations exceed the WHO limit of 
$0.4 \mathrm{mg} \mathrm{Mn} / \mathrm{L}(\mathrm{WHO}, 2011)$ by a factor of $2-5$, and the water tastes noticeably saline. Based on these findings of this small survey of deep tubewells, a depth range of 150-180 $\mathrm{m}$ with light grey sediments is recommended for the construction of new wells.

The finding of an "intermediate depth" at which water which is safe not only with regard to arsenic but also with regard to salinity and manganese is echoed by Hossain et al. (2012), who found good quality groundwater at $120 \mathrm{~m}$ in Chandpur, one of the most highly arsenic-affected areas in the country. Groundwater from this depth contained moderate levels of iron $(2-4 \mathrm{mg} / \mathrm{L})$, but iron in the region is also common in shallow groundwater $(\sim 10 \mathrm{mg} / \mathrm{L})$, and locals are accustomed to the metallic taste.

The surveys in Monoharganj have shown that the concentrations of arsenic, manganese and salinity as a function of depth are locally highly variable and that the best depth for water extraction should be determined in each community in which a larger number of deep tubewells are planned. Finding a depth with acceptable water can be difficult in some locations, and newly installed deep tubewells often deliver water that is too saline or that contains high manganese concentrations. Methods are being developed that allow drillers to test the water quality during the drilling process and to install well screens at the optimal depth.

More generally, high salinity in deep tubewells is also common in parts of the coastal zone as well as in the Sylhet basin, and manganese concentrations frequently exceed both the government limit of $0.1 \mathrm{mg} / \mathrm{L}$ and the WHO health-based value (WHO, 2011) in central and northern Bangladesh (UNICEF/BBS, 2011). Owners have reported damaged pumps that apparently corroded more quickly due to high salinity.

\section{Conclusions}

These studies have shown that there is considerable agreement between the wishes of the institutional stakeholders and rural householders with respect to the preferred mitigation options, namely, piped water and deep tubewells. Further, there is agreement between institutional stakeholders and householders about cost. However, the institutional stakeholders were of the opinion that a distance of 0-250 m (or 10-30 min) per trip was acceptable, whereas householders perceived water collection as time-consuming and hard work.

These studies also showed that there would be significant potential for reducing the number of people exposed to arsenic if householders used the safe-water options available to them. They also showed that information alone would not be enough to change people's habits. Evidence-based behaviour change techniques to increase commitment would be required.

With respect to deep tubewells in the Sreenagar district, it was found that, although free of arsenic, water taken at depth can be saline and contain unacceptably high manganese concentrations. Water taken from intermediate depths $(140-180 \mathrm{~m})$ fulfilled the quality requirements. Further, pumping tests showed that the deeper aquifer was to a large extent separated from the upper aquifer, so that the abstraction of small amounts of water for drinking using hand pumps can be deemed safe as long as wells are periodically tested. 


\section{Recommendations}

The institutional stakeholders identified a lack of capacity at the level of the locally elected sub-district councils (upazila parishad). They also mentioned a lack of accountability and coordination between organisations. These appear to be good starting points to improve mitigation outcomes.

The role of awareness creation appears to the institutional stakeholders to be an important factor in reducing exposure to arsenic, while the results of the behavioural change study indicate that the introduction of simple behaviour change techniques to "empower" the local population to make use of existing facilities, particularly well-sharing and deep tubewells, could make a significant difference to the number of people at risk.

With respect to deep tubewells, it must be remembered that groundwater quality is spatially highly variable and that safe zones within the deep (or intermediate) aquifer are site-specific. It is therefore recommended that in areas where deep tubewells are to be installed, safe depth zones should be identified by surveying existing deep tubewells and, if possible, by the installing of a small number of monitoring wells, which could also serve as sources of drinking water. Maps can be very useful. 


\title{
9.3 Multi-criteria decision analysis to evaluate fluoride-removal options in Ethiopia
}

\author{
Hong Yang, Lars Osterwalder, Richard B. Johnston, C. Annette Johnson
}

\section{Background}

Multi-Criteria Decision Analysis (MCDA) is a technique for comparing and evaluating different options (or measures) in order to identify options with the broadest acceptance, or to rank options or to distinguish acceptable from unacceptable options.

In a workshop, stakeholders with different perspectives (e.g. regional government agencies and householders) select criteria important to them which they can use to compare different options. A list of criteria is then made that all stakeholders can accept, and then the options are valuated with the help of the criteria. The list is interactive and facilitates transparent and participatory assessment. MCDA can foster collaboration and learning in a situation in which a diversity of interests are openly represented.

There are different approaches within the MCDA family. The selection of commonly used approaches, which include Multi-Attribute Value Theory (MAVT), Multi-Attribute Utility Theory (MAUT), Analytical Hierarchy Process (AHP) and the Simple Multi-Attribute Rating Technique (SMART), depends on both the nature of the question and the experience and educational level of the stakeholders involved (Kiker et al., 2005). The MAVT is one of the most commonly used approaches, partly because it has conceptually straightforward procedures that are relatively easily understood (Karjalainen et al., 2013).

The MAVT procedure consists of following steps:

1 Establishing the decision context

2 Identifying the options

3 Identifying objectives and criteria

4 Scoring

5 Weighting

6 Obtaining an overall value

7 Calculating values

8 Examining the results

Here we illustrate the MAVT procedure used in a workshop to evaluate different fluoride removal technologies in Ethiopia. See Osterwalder et al. (2014) for a description of MAVT procedure and technical information presented at the workshop.

The purpose of the workshop was to bring the different stakeholders together to discuss fluoride-removal options for drinking water and what factors, particularly cost, need to be considered when selecting a method for implementation. 


\section{Procedure}

\section{Step 1. Establishing the decision context}

Information is needed by decision-makers as a basis for deciding among alternatives. The decision context determines to some degree what information is required. The decision context is governed by policy, administrative and technical issues and the social context. Stakeholders and other key players who should be involved in the decision context need to be identified, as does the extent of their participation in the analysis. Not all stakeholders need to participate physically in the MCDA, but their values should be represented by one or more key players who do participate. The decision context is decided on at the beginning; e.g. "Sustainable fluoride-free water solutions for rural households in Ethiopia".

On 27th April 2012, a one-day stakeholder MAVT workshop was held in Addis Ababa with around 40 representatives from the federal government, regional governments, nongovernmental organisations and academia. The aim was to assess fluoride-removal technologies appropriate for rural Ethiopia.

Workshop participants were asked to evaluate the technologies for each of three scenarios (Table 9.1) with different fluoride concentrations, water consumption and water scarcity. In addition, the acceptance of bone char filter material and water salinity were considered. In plenary discussion, stakeholder groups evaluated the different options for the three scenarios using the MAVT approach. Because of time constraints, the research team preselected technologies and criteria based on interviews with 10 institutional stakeholders held early in 2012. Background information for each technology, for example, costs and technological requirements, were also collated in preparation for the workshop.

Table 9.1 Parameters of the three scenarios

\begin{tabular}{|l|l|l|l|}
\hline Variable & Case 1 & Case 2 & Case 3 \\
\hline Water consumption per unit (L/day) & 3,000 & 7,500 & 15,000 \\
\hline Fluoride concentration in raw water (mg/L) & 5 & 10 & 10 \\
\hline Acceptance of bone char & $95 \%$ & $100 \%$ & $95 \%$ \\
\hline Acceptance of slightly salty water & $100 \%$ & $95 \%$ & $95 \%$ \\
\hline Water scarcity & yes & no & no \\
\hline
\end{tabular}




\section{Step 2. Identifying the options}

The options within the decision context need to be selected.

The five technologies illustrated in Figure 9.9 were selected for the MAVT exercise. Provision of fluoride-free water was excluded because, although it is the long-term option of choice for the National Fluorosis Mitigation Project Office (NFMPO) of the Ministry of Water and Energy in Ethiopia, in the short term, it is fluoride-removal options that are needed. Technologies that have been implemented in other countries (e.g. electrocoagulation; Gwala et al., 2010) or which are under development in Ethiopia (e.g. aluminium oxide; Shimelis et al., 2005) were not considered here, as the stakeholders present at the 2012 workshop thought it would be premature to include them. An important criterion for the selection of technologies for the stakeholders was maturity.
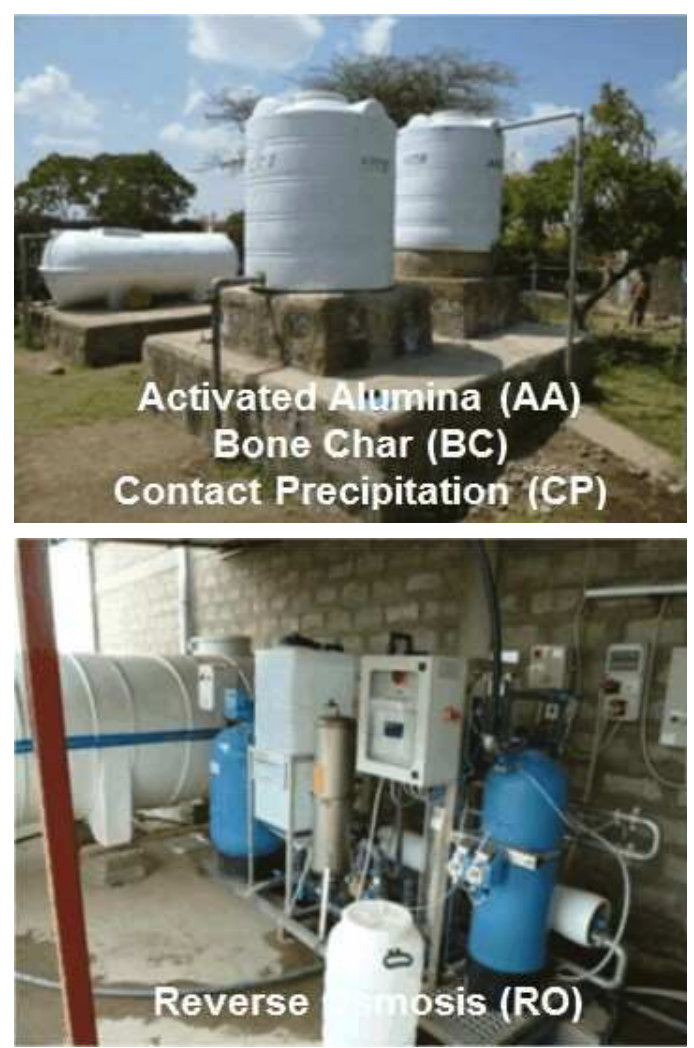

Fig. 9.9 Selected fluoride removal technologies

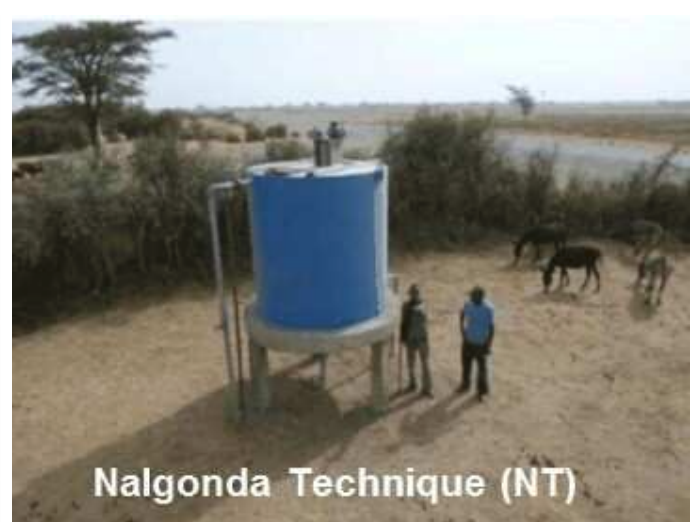

AA Filtration with granulated alumina.

BC Filtration with charred, crushed and washed animal bones filter material.

$\mathrm{CP}$ Filtration with $\mathrm{BC}$ and calciumphospahte pellets (to increase filter life).

NT Co-precipitation by addition of alum and lime to water, rapid stirring followed by setting.

RO Filtration through membrane.

\section{Step 3. Identifying the objectives and criteria}

To be able to rate and compare the different safe water options, a number of criteria need to be agreed on. These could, for example, be the costs involved, their technical performance, their accessibility to all in the community or the lifespan of technologies or machinery involved.

Three objectives with which to compare the different options - reliability, acceptability and affordability - were identified together with measurable criteria (Table 9.2). 
Table 9.2 Criteria selected in Step 3 for the assessment of fluoride-removal technologies in Ethiopia

\begin{tabular}{|c|c|c|}
\hline Objectives & No. & Criteria \\
\hline \multirow{4}{*}{$\begin{array}{l}\text { High reliability } \\
\text { (technical) }\end{array}$} & 1 & Simplicity of operation \\
\hline & 2 & Electricity requirement \\
\hline & 3 & Frequency of major repairs and/or replacements \\
\hline & 4 & Local availability of raw materials and spare parts \\
\hline \multirow{4}{*}{$\begin{array}{l}\text { High } \\
\text { acceptability } \\
\text { (social, political, } \\
\text { environmental) }\end{array}$} & 5 & Cultural acceptance \\
\hline & 6 & Water aesthetics \\
\hline & 7 & Drinking-water standards \\
\hline & 8 & Waste management \\
\hline \multirow{4}{*}{$\begin{array}{l}\text { High } \\
\text { affordability } \\
\text { (financial) }\end{array}$} & 9 & Capital costs \\
\hline & 10 & Capital maintenance costs \\
\hline & 11 & Operational costs \\
\hline & 12 & Total costs \\
\hline
\end{tabular}

\section{Step 4. Scoring}

The next step is to determine values for the criteria and to give them comparative scores. Each evaluation needs to be turned into a score. Normally, the scale extends from 0 to 1 , 10 or 100. This is necessary in order to be able to combine different types of values, for example numerical values and qualitative ratings (poor, medium, good). More detail on scoring can be found in the MCDA manual of the Department of Communities and Local Government (2009).

As an example, criteria attributes and scores are shown for Case 1 (Table 9.3). In the case study presented here, the stakeholders strongly objected to the 0 value for the minimum score and weight. We therefore assigned the scale from 1 to 10 for both score and weight. The sensitivity analysis indicated that this scale range did not alter the final ranking of different options. The background to criteria attributes and scores is given in Osterwalder et al. (2014). It should be noted that some attributes are location-specific, while others are not. Exclusion factors also needed to be considered, as not all technologies are suitable for all settings. These were: 
- if the total cost of producing treated water were to exceed $100 \mathrm{ETB} / \mathrm{m}^{3}$

- if less than $70 \%$ of the target population were to accept the technology, either for cultural or religious reasons or because of taste

- if fluoride concentrations $<1.5 \mathrm{mg} / \mathrm{L}$ could not be achieved

- if major interventions were to be necessary less than every 60 days

- if the technology were to produce a high volume of contaminated, non-potable water in a water-scarce area. This applied primarily to RO.

Table 9.3 Criteria attributes and scores for the reliability objective for Case 1 (Step 4). In Case 1, $R O$ is excluded because of water scarcity.

\begin{tabular}{|c|c|c|c|c|}
\hline Objective & Reliability & & & \\
\hline Criteria & $\begin{array}{l}\text { Operation } \\
\text { simplicity }\end{array}$ & $\begin{array}{l}\text { Electricity } \\
\text { requirement }\end{array}$ & $\begin{array}{l}\text { Frequency of } \\
\text { major } \\
\text { interventions }\end{array}$ & $\begin{array}{l}\text { Local availability of raw } \\
\text { materials and spare } \\
\text { parts }\end{array}$ \\
\hline
\end{tabular}

\section{Criteria attributes}

\begin{tabular}{|c|c|c|c|c|}
\hline Units & - & Yes/No & Days & Points \\
\hline AA & Easy & No & 431 & 6.7 \\
\hline BC & Easy & No & 204 & 10.0 \\
\hline CP & Medium & No & 480 & 6.7 \\
\hline NT & Medium & Yes & 513 & 10.0 \\
\hline RO & Difficult & Yes & 90 & 0.0 \\
\hline \multicolumn{5}{|c|}{ Criteria scores } \\
\hline AA & 10 & 10 & 7 & 0 \\
\hline BC & 10 & 10 & 0 & 10 \\
\hline CP & 0 & 10 & 9 & 0 \\
\hline NT & 0 & 0 & 10 & 10 \\
\hline RO & n.a. & n.a. & n.a. & n.a. \\
\hline
\end{tabular}




\section{Step 5 Weighting the criteria}

Stakeholders assign weights to each of the criteria to reflect their relative importance for the decision. Usually, different stakeholder groups will have different opinions on the importance of the various criteria and will therefore assign weights differently.

In this example, we are using weights on a scale from 1 to 10 . The most important criteria will therefore be assigned a weight of 10 and the least important a weight of 1 , with the remaining criteria weighted in between.

Table 9.4 Weighting of criteria by the different stakeholders (most important $=10$ )

\begin{tabular}{|c|c|c|c|c|c|}
\hline Criteria & $\begin{array}{l}\text { Federal } \\
\text { Gov. }\end{array}$ & $\begin{array}{l}\text { Local } \\
\text { Gov. }\end{array}$ & NGOs & Acad. & Arithmetic mean \\
\hline Local availability & 10 & 10 & 10 & 9 & 9.7 \\
\hline Simplicity of operation & 10 & 10 & 10 & 6 & 8.9 \\
\hline Drinking-water standards & 10 & 6 & 8 & 10 & 8.5 \\
\hline Cultural acceptance & 9 & 6 & 6 & 8 & 7.2 \\
\hline Water aesthetics & 7 & 4 & 8 & 9 & 7.0 \\
\hline Operational costs & 5 & 10 & 6 & 4 & 6.4 \\
\hline $\begin{array}{l}\text { Frequency of major } \\
\text { interventions }\end{array}$ & 6 & 0 & 10 & 8 & 5.9 \\
\hline Total costs & 8 & 8 & 4 & 3 & 5.8 \\
\hline Waste management & 6 & 0 & 8 & 7 & 5.2 \\
\hline Capital maintenance costs & 5 & 6 & 6 & 2 & 4.8 \\
\hline Capital costs & 7 & 8 & 2 & 1 & 4.5 \\
\hline
\end{tabular}

The results of criteria weighting revealed that the local availability of raw materials and simplicity of operation are major points of concern. Further, a majority of the stakeholders put a high priority on the fact that the Ethiopian national guideline needs to be met, and the treated water needs to be accepted by the consumer. Different stakeholder groups prioritised different criteria in different ways (Table 9.4). Participants from central government authorities considered capital costs more important, while the representatives of local governments put a higher priority on operational costs, reflecting the fact that the central government often pays for construction, leaving local governments to supervise operation and management. Academics and, to a lesser extent, NGOs and development partners, tended to place a higher priority on aesthetics and a lower priority on costs, perhaps reflecting concerns about sustained use. 


\section{Step 6. Obtaining an overall value}

The scores for each criterion are multiplied by the given weights to gain one final, overall value for each mitigation option. This can be mathematically expressed as

$$
V(A)=\Sigma w_{i} \cdot v_{i}\left(a_{i}\right)
$$

In the above equation, the scores given for each criterion $\left(v_{i}\left(a_{i}\right)\right)$ are multiplied by their given weights $\left(w_{i}\right)$, and these weighted scores are then summed up to gain the final, overall value $V(A)$ for mitigation option $A$.

\section{Step 7. Examining the results}

The results can be examined to determine the ranking of options.

The results of the MAVT study are given in Table 9.5 and Figure 9.10. In Case 1, high costs and water scarcity resulted in the exclusion of RO. In Case 2, the high fluoride content was the cause of the elimination of $\mathrm{BC}$, as the filter material would have to be replaced too often. In cases 2 and 3, NT was excluded because the WHO guideline value of $1.5 \mathrm{mg} / \mathrm{L}$ could not be achieved. Because of the relatively high water requirements and elevated fluoride concentrations, filtration was not suitable, leaving only RO as the remaining option.

Table 9.5 Ranking of preferred options using the average weighting for Case 1

\begin{tabular}{|l|l|l|l|}
\hline & Case 1 & Case 2 & Case 3 \\
\hline & BC & CP & RO \\
\hline Ranked options & AA & AA & \\
& NT & RO & \\
& CP & & \\
\hline $\begin{array}{l}\text { Excluded } \\
\text { options }\end{array}$ & RO & BC and NT & AA, BC, CP and NT \\
\hline
\end{tabular}

Figure 9.10 shows stakeholder preferences for Case 1. There was a large degree of agreement among the different stakeholder groups. All favoured filtration with $\mathrm{BC}$ or $\mathrm{AA}$ and gave filtration using CP and NT the lowest rankings. 


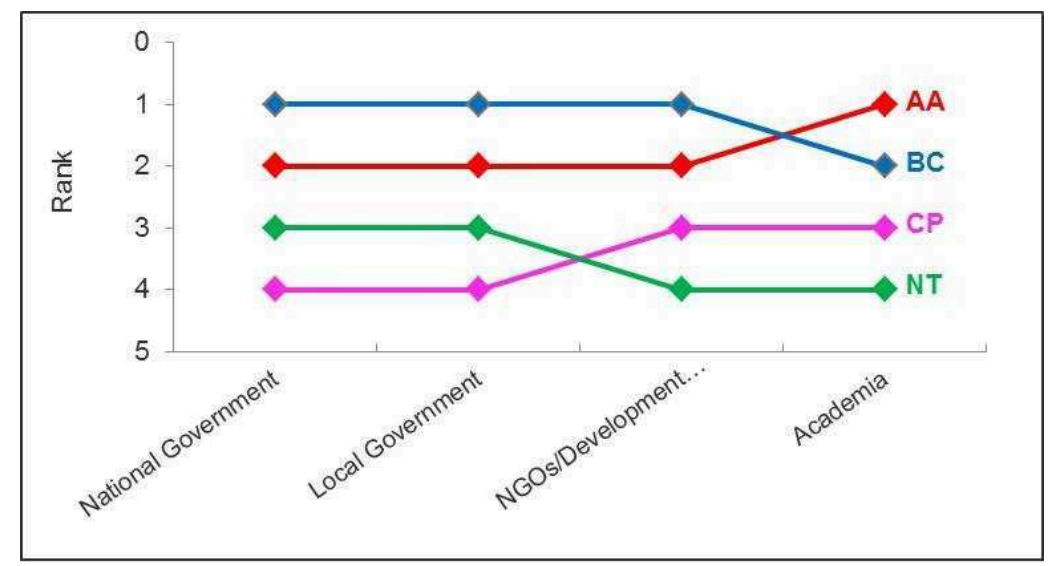

Fig. 9.10 Stakeholder preferences for Case 1

\section{Step 8. Sensitivity analysis}

The calculated results of an MCDA may be sensitive to changes in the scores and weights assigned to the options and criteria. Even small changes in weighting or scoring may lead to a completely different option being the "preferred option". In projects that attract public interest, the choice of weights may also be controversial. A sensitivity analysis can highlight these kinds of problems and provide a means for examining the extent to which vagueness about the inputs, or disagreements between stakeholders, makes a difference to the final results. The MCDA manual of the Department of Communities and Local Government (2009) describes details on how to undertake a sensitivity analysis.

\section{Conclusions and feedback}

Although there was a little scepticism at the beginning of the workshop, all agreed at the end of the day that the workshop had been very useful. First and foremost, the participants were of the opinion that it had been useful to have quantitative data that allowed them to discuss and compare different options objectively. Secondly, the participants valued being able to see for themselves that there is no single, most preferable technical solution for fluoride removal in Ethiopia and that the selection of a technology depends on location-specific parameters and on the relative importance put on different criteria by the stakeholders involved. Thirdly, it was interesting for all to note that there was good agreement between stakeholders in the selection of options. The necessity of examining different financing strategies also became clearer through the separation of costs (into capital, capital maintenance and operational costs).

In the absence of an MAVT, different sets of stakeholders tend to prioritise one option, perhaps because their organisation is promoting it. Other stakeholders may exclude one option by considering only one single criterion, sometimes without the support of empirical evidence, e.g. "reverse osmosis is too expensive" or "bone char is not acceptable to consumers". The MAVT exercise helped to provide a more objective view of the different options. Stakeholder groups could argue for different weightings for different criteria, but 
9 Case studies and applications

not for specific technologies.

Ideally, the MAVT procedure should be repeated with all stakeholders, as more information on existing technologies, or on new ones, including fluoride-avoidance options, becomes available. The methodology can easily be expanded to include more information about conditions specific to a particular location. 


\subsection{Evaluating fluoride intake via food and water using a Material Flow Analysis}

Hans-Peter Bader, Ruth Scheidegger

In the Ethiopian Rift Valley, $41 \%$ of all the sources of drinking water have fluoride concentrations exceeding the World Health Organization guideline value of $1.5 \mathrm{mg} / \mathrm{L}$ and dental and skeletal fluorosis is widespread (Tekle-Haimanot et al., 2006). In an effort to mitigate disease related to fluoride intake, water treatment options are being sought and tested (see Section 9.1 for an example). As listed in Table 3.3 (Chapter 3), the daily maximum fluoride intake is around $1.5 \mathrm{mg}$ for infants and $10 \mathrm{mg}$ for adults. From these figures, it is clear how easily these limits can be reached by drinking contaminated water. However, there is also a fluoride input via food and food preparation (using contaminated water for cooking).

In order to make daily intake estimates, it is necessary to know, firstly, the pathways along which substances can be taken up by the body. These pathways may be, for example, via beverages, food, inhalation (air), medication or personal care products (pathway analysis). Secondly, we need to quantify the amount of the substance of concern per pathway. Material Flow Analysis (MFA) is very helpful in this.

MFA is a method designed to account systematically for the material, substance and energy use of a defined system. Based on an economic input-output analysis (Leontief, 1936), MFAs were originally developed in the chemical engineering sector for process optimisation. In the mid-1980s, these methods were further developed by Baccini and Brunner (1991) to account for the material, substance and energy flows in whole regions. The MFA was extended by Baccini and Bader (1996) to yield Mathematical Material Flow Analysis, which incorporated modelling concepts to provide a systematic description and simulation of substance flows through a defined system. In the past two decades, this method has been applied to many problems in different fields and on different scales (for an overview, see Schaffner et al., 2009).

The procedure consists of four steps:

1 Model approach

2 System analysis

3 Data collection and calibration

4 Simulation, including sensitivity analysis 


\section{The MFA procedure}

The MFA procedure is shown in the following four subsections using the example of fluoride intake by children in the Ethiopian Rift Valley, based on the work of Malde et al (2011).

\section{Model approach}

The model approach used in our example is the so-called "consumption recipe model". It is based on a knowledge of nutrient or contaminant concentrations in beverages and foodstuffs and on the average daily consumption of these beverages and foodstuffs, either alone or as ingredients in different dishes. For a more detailed description of the model, see Malde et al. (2011).

\section{System analysis}

In the first step, we need to define the system to be modelled. Our example comprises the preparation of food and its consumption by a child. These two activities are defined as "processes" and are represented by boxes within the system boundary. In Figure 9.11, the processes are termed kitchen and child.

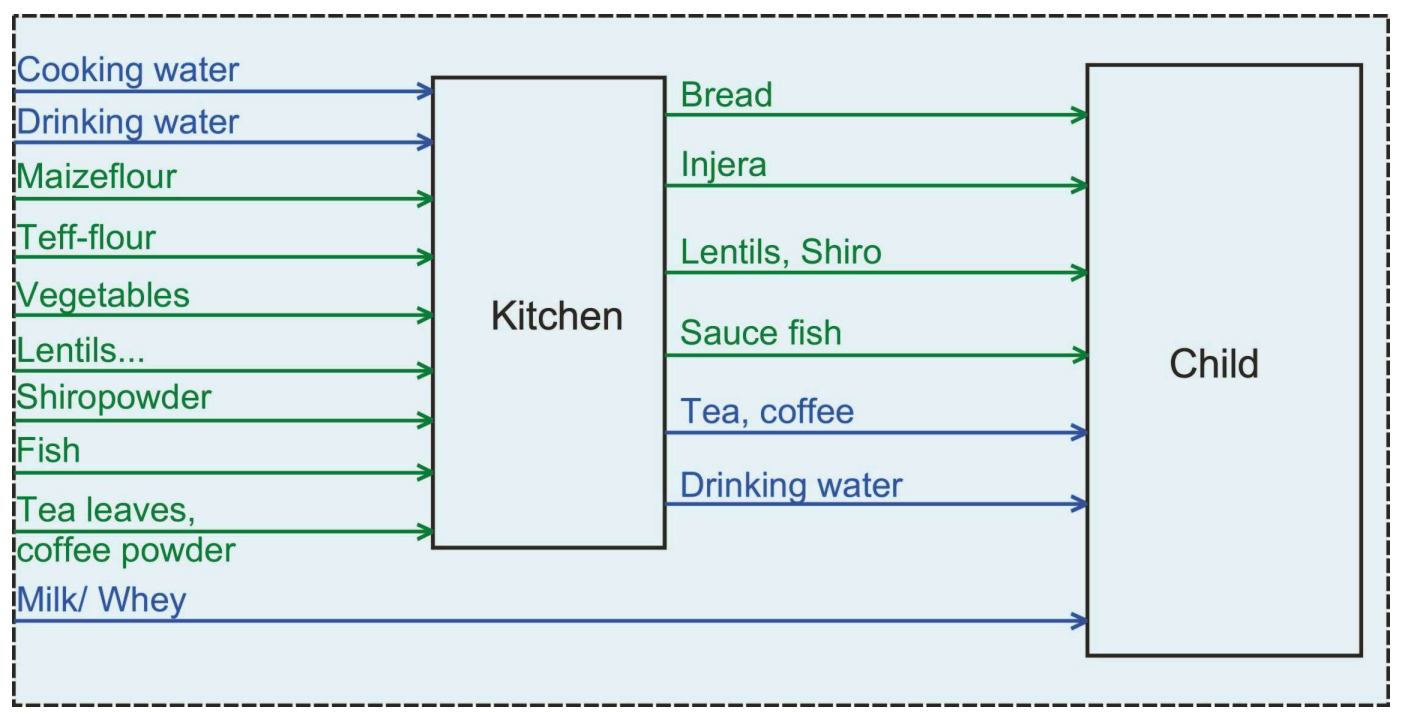

Fig. 9.11 System analysis of the intake of fluoride through food and beverages by a child in Ethiopia. Blue lines represent beverages and green lines food. For simplicity, all drinking water, even if it not used to prepare coffee or tea, is considered to pass through the process, "kitchen". Shiro powder is a mix of chickpea powder.

The next step is to determine the pathways by which the intake of fluoride occurs. Of the possible pathways (inhalation, medication and cosmetics, beverages and food), only beverages and food are relevant in the Ethiopian Rift Valley, as there are no factories there emitting fluoride into the air, and little medication, toothpaste or cosmetics are used. In our example, two groups of intake pathways can be identified: (i) Ingredients used in cooking, such as water, vegetables, fish, etc., and (ii) Products that are directly consumed (i.e., milk and whey). The ingredients of a typical meal are shown in Figure 9.12. 


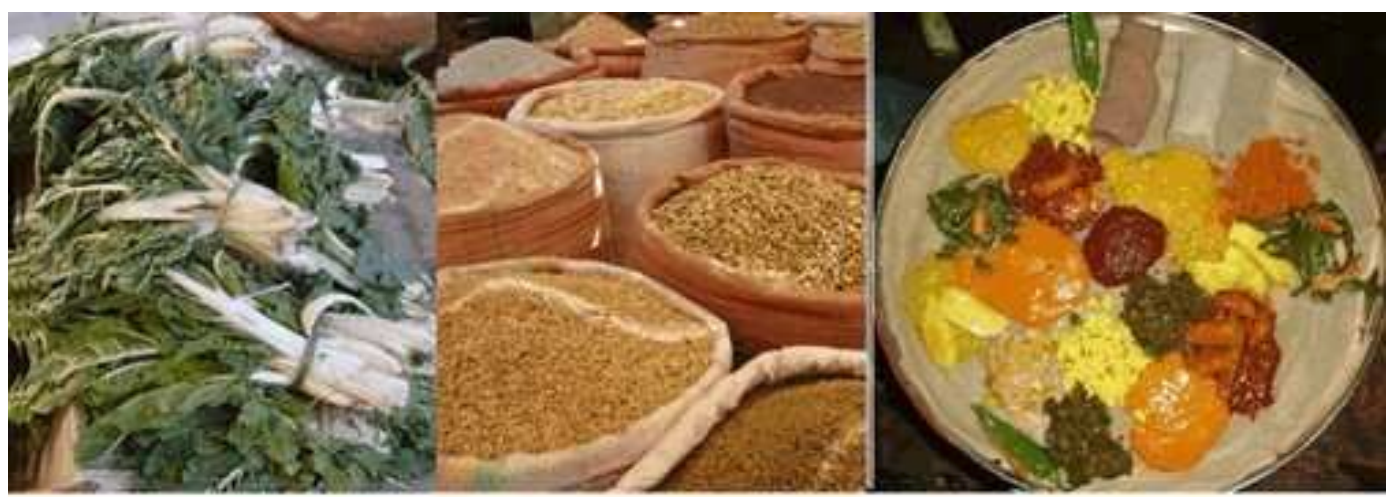

Fig. 9.12 Gomen (Ethiopian greens) (left), different types of lentils and beans (middle) and traditional dishes served on injera (traditional Ethiopian "bread") (right)

\section{Data collection and calibration}

In order to run the model described above, the following data are needed:

- The daily consumption of food and beverages

- Recipes

- Fluoride concentrations in the ingredients used

- Fluoride concentrations in prepared dishes (using the duplicate method)

Possible data sources are: field studies, literature, interviews with experts, estimates and surveys (questionnaire_about_diet, questionnaire_about_recipes). Clearly the data must be checked carefully and compared with data from other sources, if available. The full data set for the case described above is presented in Malde et al. (2011) and references therein. Using this data set, all flows of fluoride shown in Figure 9.11 were calculated.

The model was calibrated by comparing the total fluoride intake calculated from the sum of the beverages and food consumed per child each day with measured intake of fluoride in dishes sampled using the duplicate method (see Malde et al., 2003, 2004).

In the duplicate method of dietary assessment, a duplicate portion of all food and drink consumed throughout the day is prepared. The identical portions are weighed and recorded. The duplicate portion is taken to the laboratory, where it is chemically analysed. Sometimes, multiple days of assessment may be combined into a single composite and then be homogenised before analysis.

http://dapa-toolkit.mrc.ac.uk 


\section{Simulation and results}

The calibrated model was used in two scenarios:

- Village A with a water source fluoride at a concentration of $2 \mathrm{mg} / \mathrm{L}$ and

- Village B with a water source fluoride at a concentration of $14 \mathrm{mg} / \mathrm{L}$

The following calculations were made:

1. The average total fluoride intake per child per day.

2. The comparison of food, food preparation and beverages to the total fluoride intake.

3. The contribution of each item to the total fluoride intake.
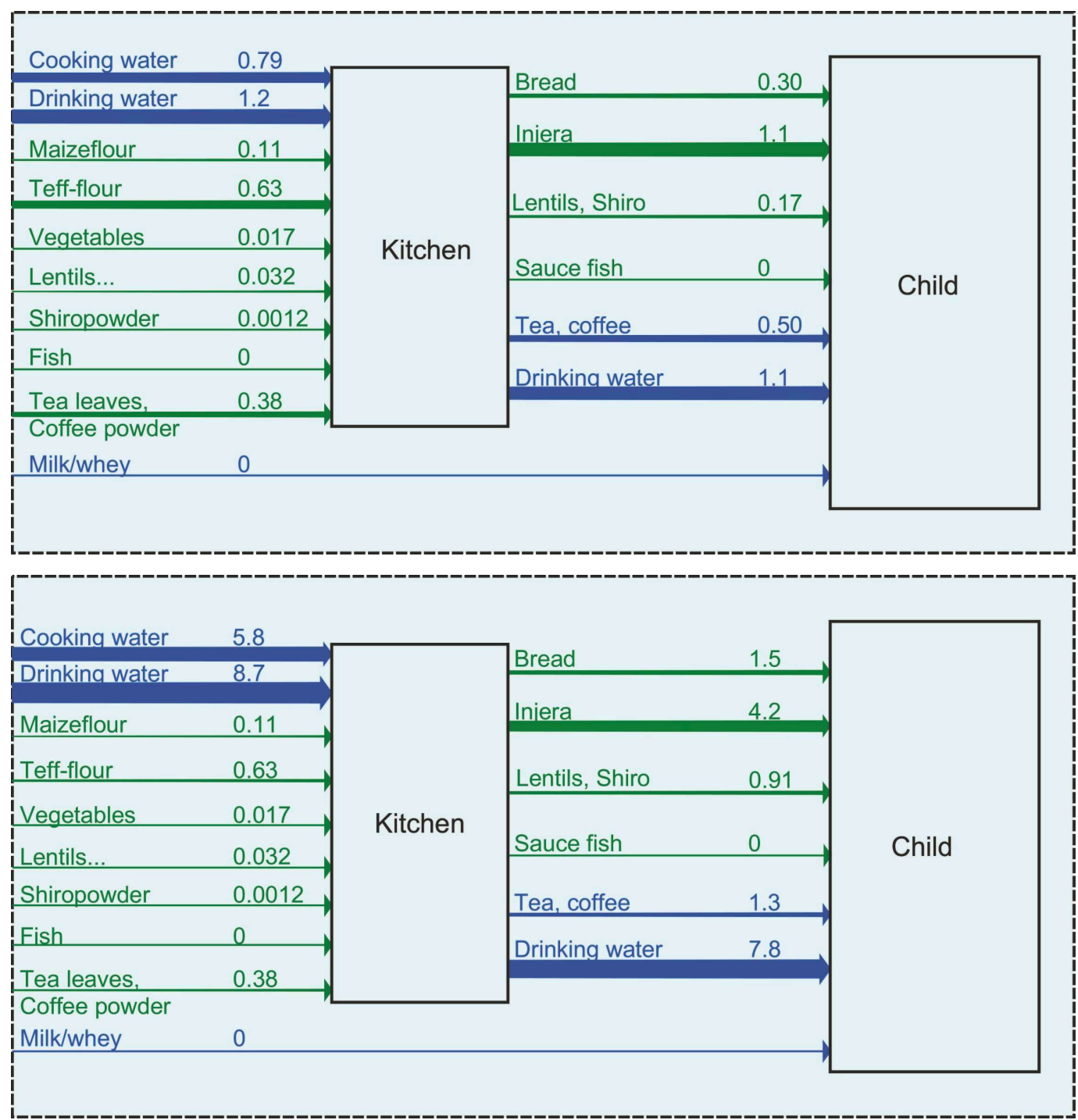

Fig. 9.13 Simplified flow diagrams summarising the flows of fluoride in food and water for Village $A$ (top) and Village $B$ (bottom). The units are $\mathrm{mg} F$ per child per day. 
The simulated fluoride flows for village A are shown in Figure 9.13 (top). From the total intake of $3.2 \mathrm{mg} \mathrm{F} /$ day per child, $38 \%$ comes from drinking water, $25 \%$ from water used for cooking and the remaining $37 \%$ from the food. The situation in village B is different (see Fig. 9.13 bottom). Here, $56 \%$ of the total intake $(16 \mathrm{mg} /$ day per child) comes from drinking water and $37 \%$ from the water used for cooking. Only $7 \%$ of the total intake comes from food. Next to water used for drinking and cooking, teff flour and tea are significant sources of fluoride.

Obviously a child living in village $B$ has a very high fluoride intake, but the fluoride intake of a child living in village $A$ is also too high. Given that the recommended maximum daily fluoride intake for children below 8 years of age is $0.1 \mathrm{mg} /$ day per $\mathrm{kg}$ of body weight, and assuming that a three-year old child weighs about $13 \mathrm{~kg}$, the child's daily intake should not be above $1.3 \mathrm{mg} /$ day (SCSEDR, 1997).

Table 9.6 Scenarios for the use of filtered water in Villages $A$ and $B$

\begin{tabular}{|c|c|c|c|c|c|}
\hline \multirow{3}{*}{ Village } & \multicolumn{5}{|c|}{ Total intake $\mathrm{mg} \mathrm{F/(child} \mathrm{and} \mathrm{day)}$} \\
\hline & \multirow[t]{2}{*}{$\begin{array}{l}\text { Current } \\
\text { situation }\end{array}$} & \multicolumn{2}{|c|}{$\begin{array}{l}\text { Drinking water } \\
\text { concentration reduced }\end{array}$} & \multicolumn{2}{|c|}{$\begin{array}{l}\text { Drinking \& cooking } \\
\text { water concentration } \\
\text { reduced }\end{array}$} \\
\hline & & $1.5 \mathrm{mg} \mathrm{F} / \mathrm{L}$ & $0 \mathrm{mg} \mathrm{F/L}$ & $1.5 \mathrm{mg} \mathrm{F} / \mathrm{L}$ & $0 \mathrm{mg} \mathrm{F} / \mathrm{L}$ \\
\hline A & 3.2 & 2.8 & 2.0 & 2.7 & 1.6 \\
\hline B & 15.7 & 7.9 & 7.0 & 2.7 & 1.6 \\
\hline
\end{tabular}

The model can now be used to simulate the effect on the average total daily fluoride intake of children if the fluoride concentration in drinking and cooking water were to be reduced to 1.5 or $0 \mathrm{mg} \mathrm{F/L}$. The results are presented in Table 9.6. The results show quite clearly that a reduction of the fluoride concentrations in drinking and cooking water to 1.5 $\mathrm{mg} / \mathrm{L}$ does not sufficiently reduce the average total daily intake of fluoride by children to the recommended maximum. The content of the water needs to be lowered further, preferably towards $0 \mathrm{mg} \mathrm{F} / \mathrm{L}$, since the food ingredients themselves already contain about $1.2 \mathrm{mg}$ F. For more details and the results of further scenarios, see Malde et. al (2011). 


\section{References and further reading}

Baccini P., Bader H.-P. (1996) Regional Stoffhaushalt. Erfassung, Bewertung und Steuerung [in German]. Heidelberg: Spektrum. Akademischer Verlag.

Baccini P., Brunner P. (1991) Metabolism of the anthroposphere. Springer, New York.Bandura A. (1997) Self-efficacy: the exercise of control. Freeman, New York.

BGS/DPHE (2001) Arsenic contamination of groundwater in Bangladesh. In: Kinniburgh D., Smedley P. (Eds.) British Geological Survey and Bangladesh Department of Public Health Engineering, Keyworth, UK.

Cialdini R.B. (2003) Crafting normative messages to protect the environment. Curr. Dir. Psychol. Sci. 12(4), 105-109.

Department of Communities and Local Government (2009) Multi-criteria analysis: A manual. Communities and Local Government Publications, London. www.communities.gov.uk/ publications/corporate/multicriteriaanalysismanual

Gollwitzer P.M. (1999) Implementation intentions: Strong effects of simple plans. Am. Psychol. 54(7), 493-503.

GTZ (2007) Multi-stakeholder management: Tools for Stakeholder Analysis: 10 building blocks for designing participatory systems of cooperation. Gesellschaft für Technische Zusammenarbeit, Eschborn, Germany www.fsnnetwork.org/sites/default/files/en-svmp-instrumenteakteuersanalyse.pdf

Gwala P., Andey S., Mhaisalkar V., Labhasetwar P., Pimpalkar S., Kshirsagar C. (2010) Lab scale study on electrocoagulation defluoridation process optimization along with aluminium leaching in the process and comparison with full scale plant operation. Water Sci. Technol. 63(12), 2788-2795.

Hossain M., Haque A., Alam S., Rahman M., Uddin M.R., Sarwar S.G., Kibia M.G., Hasan R., Ahmed K.M., Hasan M.A., Alam J., Bhattacharya P., Jacks G., von Brömssen M. (2012) Potentiality of intermediate depth aquifer as a source of arsenic and manganese safe tubewells in Bangladesh. Presented at the 4th International Congress on Arsenic in the Environment, As 2012, Cairns, Australia, 71-73.

Howard G., Ahmed M.F., Shamsuddin A.J., Mahmud S.G., Deere D. (2006) Risk assessment of arsenic mitigation options in Bangladesh. J. Health Popul. Nutr. 24(3), 346-355.

Huber A.C., Bhend S., Mosler H.-J. (2012). Determinants of exclusive consumption of fluoride-free water: A cross-sectional household study in rural Ethiopia. J. Pub Health 20(3), 269-278

Huber A.C., Mosler H.-J. (2012). Determining behavioral factors for interventions to increase safe water consumption: A cross-sectional field study in rural Ethiopia. Int. J. Environ. Health Res. 23(2),1-12.

Huber A.C., Tobias R., Mosler H.-J. (2014). Evidence-based tailoring of behavior-change campaigns: Increasing fluoride-free water consumption in rural Ethiopia with persuasion. Appl. Psychol. Health Well Being 6(1), 96-118.

Hug S.J., Gaertner D., Roberts L.C., Schirmer M., Ruettimann T., Rosenberg T.M., Badruzzaman A.B.M., Ali M.A. (2011) Avoiding high concentrations of arsenic, manganese and salinity in deep tubewells in Munshiganj District, Bangladesh. Appl. Geochem. 26(7), 1077-1085.

Inauen J., Mosler H.-J. (2013) Developing and testing theory-based and evidence-based interventions to promote switching to arsenic-safe wells in Bangladesh. J. Health Psychol. http://dx.doi.org/10.1177/1359105313493811

Inauen J., Hossain M.M., Johnston R.B., Mosler H.-J. (2013a) Acceptance and use of eight arsenic-safe drinking water options in Bangladesh. PLOS One 8(1), e53640.Inauen J., Tobias R., Mosler H.-J. (2013b) Predicting water-consumption habits for seven arsenic-safe water options in Bangladesh. BMC Pub. Health 13, 417. 
Inauen J., Tobias R., Mosler H.-J. (2013c) The role of commitment strength in enhancing safe water consumption: Mediation analysis of a cluster-randomised trial. Brit. J. Health Psychol. http://dx.doi.org/10.1111/bjhp.12068.

IRC (2011) Briefing Note 1a: Life-cycle costs approach. IRC International Water and Sanitation Centre, The Netherlands.

Johnston R., Hug S.J., Inauen J., Khan N.I., Mosler H.-J., Yang H. (2014) Enhancing arsenic mitigation in Bangladesh: Findings from institutional, psychological, and technical investigations. Sci. Tot. Environ. 448-449, 477-483.

Karjalainen T.P., Rossi P.M., Ala-aho P., Eskelinen R., Reinikainen K., Kløve B., Pulido-Velazquez M., Yang H. (2013) A decision analysis framework for stakeholder involvement and learning in groundwater management. Hydrol. Earth Syst. Sci. Discuss. 10, 8747-8780.

Khan N.I., Brouwer R., Yang H. (2014) Household willingness to pay for arsenic-free drinking water in Bangladesh. J. Environ. Manag. In press.

Khan N.I., Yang H. (2014) Arsenic mitigation in Bangladesh: An analysis of institutional stakeholders' opinions. Sci. Total Environ. 448-449(1), 493-504.

Kiker G.A., Bridges T.S., Varghese A., Seager T.P., Linkov I. (2005) Application of multicriteria decision analysis in environmental decision making. Integr. Environ. Assess. Manag. 1(2), 95108.

Leontief W. (1936) Quantitative input and output relations in the economic system of the United States. Rev. Econ. Stat. 18, 105-125.

Malde M.K, Maage A., Macha E., Julshamn K., Bjorvatn K. (1997) Fluoride content in selected food items from five areas in East Africa. J. Food Compos. Anal. 10(3), 233-245.

Malde M.K., Zerihun L., Julshamn K., Bjorvatn K. (2003) Fluoride intake in children living in a highfluoride area in Ethiopia. Intake through beverages. Int. J. Paed. Dentistr. 13(1), 27-34.

Malde M.K., Zerihun L., Julshamn K., Bjorvatn K. (2004) Fluoride, calcium and magnesium intake in children living in a high-fluoride area in Ethiopia. Intake through food. Int. J. Paed. Dentistr. 14(3), 167-174.

Malde M.K., Scheidegger R., Julshamn K., Bader H.-P. (2011) Substance flow analysis - A case study of fluoride exposure through food and beverages in young children living in Ethiopia. Environ Health Perspect. 119(4), 579-584. http://dx.doi.org/10.1289/ehp.1002365

Mosler H.-J. (2012) A systematic approach to behavior change interventions for the water and sanitation sector in developing countries: A conceptual model, a review, and a guideline. Int. J. Environ. Health. Res. 22(5), 431-449.

Osterwalder L., Johnson C.A., Yang H., Johnston R.B. (2014) Multi-criteria assessment of community-based fluoride-removal technologies for rural Ethiopia. Sci. Total Environ. 448-449, 532-538.

Rango T., Kravchenko J., Atlaw B., McCornick P.G., Jeuland M., Merola B., Vengosh A. (2012) Groundwater quality and its health impact: An assessment of dental fluorosis in rural inhabitants of the Main Ethiopian Rift. Environ. Internat., 43 (2012) 37-47.

Schaffner M., Bader H.-P., Scheidegger R. (2009) Modeling the contribution of point sources and non-point sources to Thachin River water pollution. Sci. Total Environ. 407(17), 4902-4915.

Schmeer K. (1999). Guidelines for conducting a stakeholder analysis. Partnerships for Health Reform, Abt Associates Inc., Bethesda, MD. www.who.int/management/partnerships/overall/en/ index1.html

Schultz P.W., Nolan J.M., Cialdini R.B., Goldstein N.J., Griskevicius V. (2007) The constructive, destructive, and reconstructive power of social norms. Psychol. Sci. 18(5), 429-434.

Shimelis B., Zewge F., Chandravanshi S. (2005) Removal of excess fluoride from water by aluminum hydroxide. Bull. Chem. Soc. Ethiop. 20(1), 17-34. 
Sonego I.L., Huber A.C., Mosler H.-J. (2013). Does the Implementation of hardware need software? A longitudinal study on fluoride-removal filter use in Ethiopia. Environ. Sci. Technol. 47(22), 12661-12668.

SSWM Toolbox, Stakeholder Analysis www.sswm.info/category/planning-process-tools/ exploring\#Stakeholder\%20Analysis

Tekle-Haimanot R., Melaku Z., Kloos H., Reimann C., Fantaye W., Zerihun L., Bjorvatn, K. (2006). The geographic distribution of fluoride in surface and groundwater in Ethiopia with an emphasis on the Rift Valley. Sci. Total Environ. 367(1), 182-190.

UNICEF Bangladesh (2011) Bangladesh national drinking water quality survey of 2009. UNICEF/ Bangladesh Bureau of Statistics, Dhaka, Bangladesh.

van Geen A., Ahmed E.B., Pitcher L., Mey J.L., Ahsanc H., Graziano J.H., Ahmed K.M. (2014) Comparison of two blanket surveys of arsenic in tubewells conducted 12 years apart in a 25 km2 area of Bangladesh. Sci. Tot. Environ. 448-449, 484-492.

Wedgwood A., Sansom K. (2003) Willingness to pay surveys - A streamlined approach. Guidance notes for small town services. Water, Engineering and Development Centre, Loughborough University. www.partnershipsforwater.net/psp/tc/TC Tools/006T Willingness\%20to\%20pay.pdf

WHO, World Health Organization (2011). Guidelines for drinking-water quality, 4th edn. World Health Organization. 